\title{
Balancing Cost and Accuracy in Quantum Mechanical Simulations on Collagen Protein Models
}

Michele Cutini, ${ }^{*}$ Irene Bechis, Marta Corno, and Piero Ugliengo*

University of Turin, Department of Chemistry and NIS (Nanostructured Interfaces and Surfaces) Center, Turin, 10125, IT

I.B. present address: Department of Chemistry, Imperial College London, Molecular Science Research Hub, White City Campus, Wood Lane, London, W12 OBZ, UK

*e-mail: michele.cutini@unito.it,piero.ugliengo@unito.it

Supporting Information 


\section{Computational Details}

Table S1. 6-31G* basis set in CRYSTAL17 basis set format.

\begin{tabular}{|c|c|c|c|c|c|}
\hline \multicolumn{3}{|l|}{ Carbon } & \multicolumn{3}{|l|}{ Oxygen } \\
\hline \multicolumn{3}{|l|}{64} & \multicolumn{3}{|l|}{84} \\
\hline \multicolumn{3}{|l|}{0062.01 .0} & \multicolumn{3}{|l|}{0062.01 .0} \\
\hline $.3047524880 \mathrm{D}+04$ & \multicolumn{2}{|c|}{ 1834737130D-02 } & $.5484671660 \mathrm{D}+04$ & \multicolumn{2}{|l|}{ 1831074430D-02 } \\
\hline $.4573695180 \mathrm{D}+03$ & \multicolumn{2}{|c|}{$.1403732280 \mathrm{D}-01$} & $.8252349460 \mathrm{D}+03$ & \multicolumn{2}{|l|}{$.1395017220 \mathrm{D}-01$} \\
\hline $.1039486850 \mathrm{D}+03$ & \multicolumn{2}{|c|}{$.6884262220 \mathrm{D}-01$} & $.1880469580 \mathrm{D}+03$ & \multicolumn{2}{|l|}{$.6844507810 \mathrm{D}-01$} \\
\hline $.2921015530 D+02$ & \multicolumn{2}{|c|}{$.2321844430 \mathrm{D}+00$} & $.5296450000 \mathrm{D}+02$ & \\
\hline $.9286662960 \mathrm{D}+01$ & \multicolumn{2}{|c|}{$.4679413480 \mathrm{D}+00$} & $.1689757040 \mathrm{D}+02$ & \multicolumn{2}{|l|}{$\begin{array}{r}.2327143360 D+00 \\
4701928980 D+00\end{array}$} \\
\hline $.3163926960 \mathrm{D}+01$ & \multicolumn{2}{|c|}{$.3623119850 \mathrm{D}+00$} & $.5799635340 \mathrm{D}+01$ & \multicolumn{2}{|l|}{$.3585208530 \mathrm{D}+00$} \\
\hline \multicolumn{3}{|l|}{0134.01 .0} & \multicolumn{3}{|c|}{0136.01 .0} \\
\hline $.7868272350 \mathrm{D}+01$ & \multicolumn{2}{|c|}{$-.1193324200 D+00 \quad .6899906660 D-01$} & $.1553961625 \mathrm{D}+02$ & \multicolumn{2}{|c|}{$-.1107775490 D+00 \quad .7087426820 D-01$} \\
\hline $.1881288540 \mathrm{D}+01$ & \multicolumn{2}{|c|}{$-.1608541520 \mathrm{D}+00 \quad .3164239610 \mathrm{D}+00$} & $.3599933586 \mathrm{D}+01$ & \multicolumn{2}{|c|}{$-.1480262620 \mathrm{D}+00 \quad .3397528390 \mathrm{D}+00$} \\
\hline $.5442492580 \mathrm{D}+00$ & \multicolumn{2}{|c|}{$.1143456440 \mathrm{D}+01 \quad .7443082910 \mathrm{D}+00$} & $.1013761750 D+01$ & \multirow{2}{*}{\multicolumn{2}{|c|}{$.1130767010 \mathrm{D}+01 \quad .7271585770 \mathrm{D}+00$}} \\
\hline 0110.01 .0 & & & 0110.01 .0 & & \\
\hline $.1687144782 D+00$ & \multicolumn{2}{|c|}{$.1000000000 D+01 \quad .1000000000 D+01$} & $.2700058226 \mathrm{D}+00$ & \multirow{2}{*}{\multicolumn{2}{|c|}{$.1000000000 D+01 \quad .1000000000 D+01$}} \\
\hline 0310.01 .0 & \multirow{2}{*}{\multicolumn{2}{|c|}{$.1000000000 D+01$}} & 0310.01 .0 & & \\
\hline $.8000000000 D+00$ & & & $.8000000000 D+00$ & $.1000000000 \mathrm{D}+01$ & \\
\hline Nitrogen & & & Hydrogen & & \\
\hline 74 & & & 13 & & \\
\hline 00662.1 & & & 00031.01 .0 & & \\
\hline $0.417351 \mathrm{E}+04$ & $0.183477 \mathrm{D}-02$ & & $.1873113696 \mathrm{D}+02$ & $.3349460434 \mathrm{D}-01$ & \\
\hline $0.627458 \mathrm{E}+03$ & $0.139946 \mathrm{D}-01$ & & $.2825394365 \mathrm{D}+01$ & $.2347269535 \mathrm{D}+00$ & \\
\hline $0.142902 E+03$ & $0.685866 \mathrm{D}-01$ & & $.6401216923 D+00$ & $.8137573262 \mathrm{D}+00$ & \\
\hline $0.402343 E+02$ & $0.232241 \mathrm{E}+00$ & & 0010.01 .0 & & \\
\hline $0.128202 \mathrm{E}+02$ & $0.469070 \mathrm{E}+00$ & & $.1612777588 \mathrm{D}+00$ & $.1000000000 \mathrm{D}+01$ & \\
\hline $0.439044 \mathrm{E}+01$ & $0.360455 E+00$ & & 0210.01 .0 & & \\
\hline 0135.1. & & & $.1100000000 \mathrm{D}+01$ & $.1000000000 D+01$ & \\
\hline $0.116264 \mathrm{E}+02$ & $-.114961 \mathrm{E}+00$ & $0.675797 \mathrm{D}-01$ & & & \\
\hline $0.271628 \mathrm{E}+01$ & $-.169117 \mathrm{E}+00$ & $0.323907 \mathrm{E}+00$ & & & \\
\hline $0.772218 \mathrm{E}+00$ & $0.114585 E+01$ & $0.740895 \mathrm{E}+00$ & & & \\
\hline 0110.1 & & & & & \\
\hline $0.212031 \mathrm{E}+00$ & $0.100000 \mathrm{E}+01$ & $0.100000 \mathrm{E}+01$ & & & \\
\hline 0310.1 . & & & & & \\
\hline $0.800000 \mathrm{E}+00$ & $0.100000 \mathrm{E}+01$ & & & & \\
\hline
\end{tabular}


Table S2. $6-311 G^{*}$ basis set in CRYSTAL17 basis set format.

\begin{tabular}{|c|c|c|c|c|c|}
\hline \multicolumn{3}{|l|}{ Carbon } & \multicolumn{3}{|l|}{ Oxygen } \\
\hline \multicolumn{3}{|l|}{65} & \multicolumn{3}{|l|}{85} \\
\hline \multicolumn{3}{|l|}{0062.01 .0} & \multicolumn{3}{|l|}{0062.01 .0} \\
\hline 4563.2400000 & \multicolumn{2}{|l|}{0.00196665} & 8588.5000000 & \multicolumn{2}{|l|}{0.00189515} \\
\hline 682.0240000 & \multicolumn{2}{|l|}{0.0152306} & 1297.2300000 & \multicolumn{2}{|l|}{0.0143859} \\
\hline 154.9730000 & \multicolumn{2}{|l|}{0.0761269} & 299.2960000 & \multicolumn{2}{|l|}{0.0707320} \\
\hline 44.4553000 & \multicolumn{2}{|l|}{0.2608010} & 87.3771000 & \multicolumn{2}{|l|}{0.2400010} \\
\hline 13.0290000 & \multicolumn{2}{|l|}{0.6164620} & 25.6789000 & \multicolumn{2}{|l|}{0.5947970} \\
\hline 1.8277300 & \multicolumn{2}{|l|}{0.2210060} & 3.7400400 & \multicolumn{2}{|l|}{0.2808020} \\
\hline \multicolumn{3}{|l|}{0134.01 .0} & \multicolumn{3}{|l|}{0136.01 .0} \\
\hline 20.9642000 & \multicolumn{2}{|c|}{$0.1146600 \quad 0.0402487$} & 42.1175000 & 0.1138890 & 0.0365114 \\
\hline 4.8033100 & \multicolumn{2}{|c|}{$0.9199990 \quad 0.2375940$} & 9.6283700 & 0.9208110 & 0.2371530 \\
\hline 1.4593300 & \multicolumn{2}{|c|}{$-0.00303068 \quad 0.8158540$} & 2.8533200 & -0.00327447 & 0.8197020 \\
\hline \multicolumn{3}{|l|}{0110.01 .0} & 0110.01 .0 & & \\
\hline 0.4834560 & 1.0000000 & & 0.9056610 & 1.0000000 & 1.0000000 \\
\hline 0110.01 .0 & & & 0110.01 .0 & & \\
\hline 0.1455850 & 1.0000000 & & 0.2556110 & 1.0000000 & 1.0000000 \\
\hline 0310.01 .0 & & & 0310.01 .0 & & \\
\hline 0.6260000 & 1.0000000 & & 1.2920000 & 1.0000000 & \\
\hline Nitrogen & & & Hydrogen & & \\
\hline 75 & & & 13 & & \\
\hline 0062.1. & & & 0031.01 .0 & & \\
\hline 6293.4800000 & 0.00196979 & & $.1873113696 \mathrm{D}+02$ & .334946 & 4D-01 \\
\hline 949.0440000 & 0.0149613 & & $.2825394365 D+01$ & .234726 & $5 \mathrm{D}+00$ \\
\hline 218.7760000 & 0.0735006 & & $.6401216923 D+00$ & .813757 & $2 \mathrm{D}+00$ \\
\hline 63.6916000 & 0.2489370 & & 0010.01 .0 & & \\
\hline 18.8282000 & 0.6024600 & & $.1612777588 D+00$ & .100000 & OD+01 \\
\hline 2.7202300 & 0.2562020 & & 0210.01 .0 & & \\
\hline 0135.1. & & & $.1100000000 D+01$ & .100000 & 0D+01 \\
\hline 30.6331000 & 0.1119060 & 0.0383119 & & & \\
\hline 7.0261400 & 0.9216660 & 0.2374030 & & & \\
\hline 2.1120500 & -0.00256919 & 0.8175920 & & & \\
\hline 0110.1. & & & & & \\
\hline 0.6840090 & 1.0000000 & 1.0000000 & & & \\
\hline 0110.1. & & & & & \\
\hline 0.2008780 & 1.0000000 & 1.0000000 & & & \\
\hline 0310.1 & & & & & \\
\hline 0.9130000 & 1.0000000 & & & & \\
\hline
\end{tabular}


Table S3. TZP basis set in CRYSTAL17 basis set format.

\begin{tabular}{|c|c|c|c|c|c|c|c|}
\hline Carbon & & Oxygen & & Nitrogen & & Hydrogen & \\
\hline 610 & & 810 & & 710 & & 13 & \\
\hline 0052.01 .00 & & 0052.01 .00 & & 0052.01 .00 & & 0031.1 .00 & \\
\hline 8506.03840 & $0.533736640 \mathrm{E}-03$ & 15902.6475 & 0.514998037E-03 & 11913.4168 & $-0.522970174 \mathrm{E}-03$ & 18.73113696 & 0.03349460434 \\
\hline 1275.73290 & $0.412502320 \mathrm{E}-02$ & 2384.95378 & 0.398197644E-02 & 1786.72138 & $-0.404284040 \mathrm{E}-02$ & 2.825394365 & 0.2347269535 \\
\hline 290.311870 & 0.211713370 E-01 & 542.719572 & $0.204769719 \mathrm{E}-01$ & 406.590128 & $-0.207727151 \mathrm{E}-01$ & 0.6401216923 & 0.8137573262 \\
\hline 82.0562000 & $0.824178600 \mathrm{E}-01$ & 153.404079 & $0.802623679 E-01$ & 114.925251 & $-0.811831378 E-01$ & 0010.1 .000 & \\
\hline 26.4796410 & 0.240128580 & 49.5457161 & 0.237668399 & 37.1058834 & -0.238714974 & 1612777588 & 1.0000000000 \\
\hline 0012.01 .00 & & 0012.01 .00 & & 0012.01 .00 & & 0210.1 & \\
\hline 9.24145850 & 1.00000000 & 17.3396499 & 1.00000000 & 12.9716762 & 1.00000000 & 1.1000000000 & 1.0000000000 \\
\hline 0010.01 .00 & & 0010.01 .00 & & 0010.01 .00 & & & \\
\hline 3.36435300 & 1.00000000 & 6.33033553 & 1.00000000 & 4.73022912 & 1.00000000 & & \\
\hline 0010.01 .00 & & 0010.01 .00 & & 0010.01 .00 & & & \\
\hline 0.871741640 & 1.00000000 & 1.69958822 & 1.00000000 & 1.25251843 & 1.00000000 & & \\
\hline 0010.01 .00 & & 0010.01 .00 & & 0010.01 .00 & & & \\
\hline 0.363523520 & 1.00000000 & 0.689544913 & 1.00000000 & 0.512600712 & 1.00000000 & & \\
\hline 0010.01 .00 & & 0010.01 .00 & & 0010.01 .00 & & & \\
\hline 0.128731350 & 1.00000000 & 0.239360282 & 1.00000000 & 0.179397140 & 1.00000000 & & \\
\hline 0242.01 .00 & & 0244.01 .00 & & 0243.01 .00 & & & \\
\hline 34.7094960 & $0.533009740 \mathrm{E}-02$ & 63.2705240 & 0.607092060E-02 & 49.2187584 & $0.555269535 \mathrm{E}-02$ & & \\
\hline 7.95908830 & 0.358658140 E-01 & 14.6233123 & 0.419476887E-01 & 11.3489353 & $0.380546180 \mathrm{E}-01$ & & \\
\hline 2.37869720 & 0.142002990 & 4.44895180 & 0.161568840 & 3.42850882 & 0.149414122 & & \\
\hline 0.815400650 & 0.342031050 & 1.52815132 & 0.356827793 & 1.17995126 & 0.348981874 & & \\
\hline 0210.01 .00 & & 0210.01 .00 & & 0210.01 .00 & & & \\
\hline 0.289537850 & 1.00000000 & 0.529973159 & 1.00000000 & 0.417261226 & 1.00000000 & & \\
\hline 0210.01 .00 & & 0210.01 .00 & & 0210.01 .00 & & & \\
\hline 0.100847540 & 1.00000000 & 0.175094460 & 1.00000000 & 0.142951313 & 1.00000000 & & \\
\hline 0310.001 .00 & & 0310.001 .00 & & 0310.001 .00 & & & \\
\hline 0.800000000 & 1.00000000 & 1.200000000 & 1.000000000 & 1.000000000 & 1.00000000 & & \\
\hline
\end{tabular}


Table S4. QZP basis set in CRYSTAL17 basis set format.

\begin{tabular}{|c|c|c|c|c|c|c|c|}
\hline Carbon & & Oxygen & & Nitrogen & & Hydrogen & \\
\hline 612 & & 812 & & 712 & & 15 & \\
\hline 0062.1. & & 0062.1. & & 0052.1 & & 0031.1 & \\
\hline 35088. & 0.000670 & 63655. & 0.000659 & 48335. & 0.001342 & 82.921 & 0.022940 \\
\hline 5257.4 & 0.005202 & 9537.6 & 0.005115 & 7242.1 & 0.010419 & 12.452 & 0.175491 \\
\hline 1196.5 & 0.027207 & 2170.7 & 0.026762 & 1648.2 & 0.054507 & 2.8330 & 0.864756 \\
\hline 338.84 & 0.112759 & 614.72 & 0.111012 & 466.76 & 0.226001 & 0010.1 & \\
\hline 110.48 & 0.387704 & 200.45 & 0.382771 & 152.20 & 0.778370 & 0.80001 & 1.0 \\
\hline 39.785 & 0.565654 & 72.230 & 0.572099 & 0020.1 & & 0010 & 1. \\
\hline 0020.1. & & 0020.1. & & 54.828 & 0.370936 & 0.25859 & 1.0 \\
\hline 39.785 & 0.188092 & 72.230 & 0.183965 & 21.209 & 0.665560 & 0010.1. & \\
\hline 15.366 & 0.835353 & 27.972 & 0.838955 & 0020.1. & & 0.089969 & 1.0 \\
\hline 0010.1. & & 0010.1. & & 21.209 & 0.106526 & 0210.1 & \\
\hline 6.2406 & 1.000000 & 11.423 & 1.000000 & 8.6404 & 0.906538 & 1.00000 & 1.000000 \\
\hline 0010.1 & & 0010.1. & & 0010.1 & & & \\
\hline 2.5893 & 1.000000 & 4.7730 & 1.000000 & 3.5990 & 1.000000 & & \\
\hline 0010.1. & & 0010.1. & & 0010.1 & & & \\
\hline 0.74105 & 1.000000 & 1.4400 & 1.000000 & 1.0622 & 1.000000 & & \\
\hline 0010.1 & & 0010.1. & & 0010.1. & & & \\
\hline 0.29334 & 1.000000 & 0.55984 & 1.000000 & 0.41529 & 1.000000 & & \\
\hline 0010.1 & & 0010.1. & & 0010.1 & & & \\
\hline 0.11187 & 1.000000 & 0.20807 & 1.000000 & 0.15609 & 1.000000 & & \\
\hline 024 4. 1 & & 0246.1 . & & 0245.1 & & & \\
\hline 61.636 & 0.008244 & 111.54 & 0.008325 & 87.205 & 0.008156 & & \\
\hline 14.444 & 0.060288 & 26.206 & 0.062300 & 20.478 & 0.060642 & & \\
\hline 4.4412 & 0.258479 & 8.1556 & 0.269698 & 6.3463 & 0.262389 & & \\
\hline 1.5716 & 0.770226 & 2.9196 & 0.757895 & 2.2624 & 0.765702 & & \\
\hline 0210.1 & & 0210.1 . & & 0210.1 & & & \\
\hline 0.59804 & 1.000000 & 1.1047 & 1.000000 & 0.86191 & 1.000000 & & \\
\hline 0210.1 & & 0210.1 . & & 0210.1 & & & \\
\hline 0.23019 & 1.000000 & 0.41368 & 1.000000 & 0.32978 & 1.000000 & & \\
\hline 0210.1 & & 0210.1 . & & 0210.1 & & & \\
\hline 0.086596 & 1.000000 & 0.14810 & 1.000000 & 0.12205 & 1.000000 & & \\
\hline 0310.1 . & & 0310.1. & & 0310.1 . & & & \\
\hline .75000 & 1.000000 & .85000 & 1.000000 & .80000 & 1.000000 & & \\
\hline
\end{tabular}




\section{Molecular Models}

In this work we have analysed in details the residues dihedral angles, see Figure S1 a), and the main inter-chains interactions in the studied collagen models, see Figure S1 b)-g). One common inter-chains contact in collagen is the $\mathrm{H}$-bond perpendicular to the helical axes which involves the $\mathrm{N}-\mathrm{H}$ group of $\mathrm{Gly}$ and the $\mathrm{C}=\mathrm{O}$ group of the amino acid in $\mathrm{X}$ position, see Figure $\mathrm{S} 1 \mathrm{~b}$ ). This electrostatic contact is usually present in any collagen triple helix regardless the aminoacidic composition as well as solvation.

Bella et al. ${ }^{1}$ highlighted from experimental evidences that other weak electrostatic contacts between collagen strands perpendicular to the helical axes may take place. These involve the $\mathrm{C}-\mathrm{H}$ groups of the residue in $\mathrm{Y}$ position (Hyp in our case) and Gly with the $\mathrm{C}=\mathrm{O}$ group of the aminoacid in $\mathrm{X}$, see Figure $\mathrm{S} 1 \mathrm{c}$ ) and d). In this way, the $\mathrm{C}=\mathrm{O}$ group of the aminoacid in $X$ is involved in three electrostatic contacts, as reported in Figure $S 1$ b), c) and d). These are summarized in Figure $\mathrm{S} 1 \mathrm{~g}$ ).

Regarding the hydroxyl group of Hyp conformation, among all possible orientation that we have explored in detail in Ref ${ }^{2}$, we pointed the $\mathrm{H}$ atom of the hydroxyl group towards the closest $\mathrm{C}=\mathrm{O}$ group (usually belonging to $\mathrm{Hyp}$ ) to have a weak electrostatic contacts, see Figure $\mathrm{S} 1 \mathrm{e}$ ). This eventually leads to another electrostatic contact involving the $\mathrm{N}-\mathrm{H}$ group of the residue in $\mathrm{X}$ position, see Figure $\mathrm{S} 1 \mathrm{f}$ ). 
a)

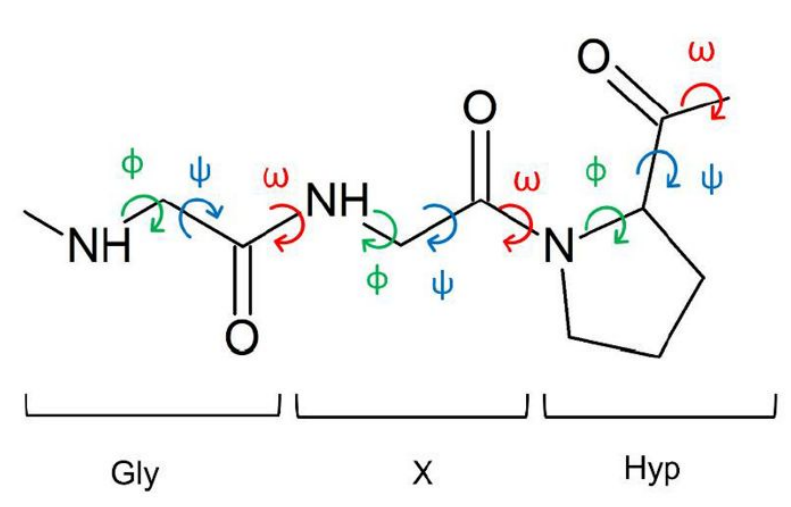

c)

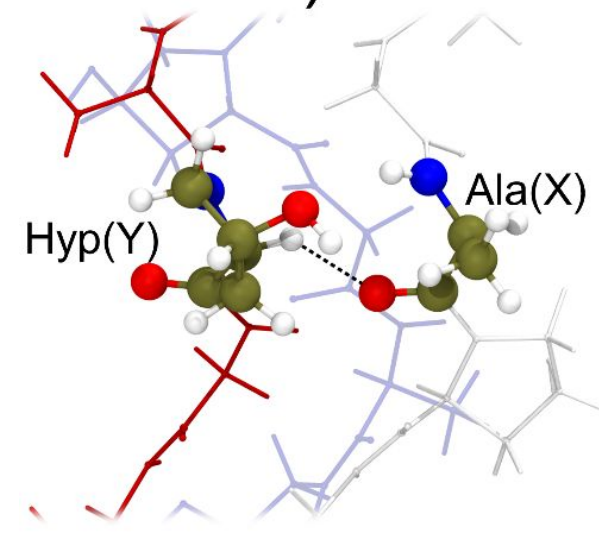

e)

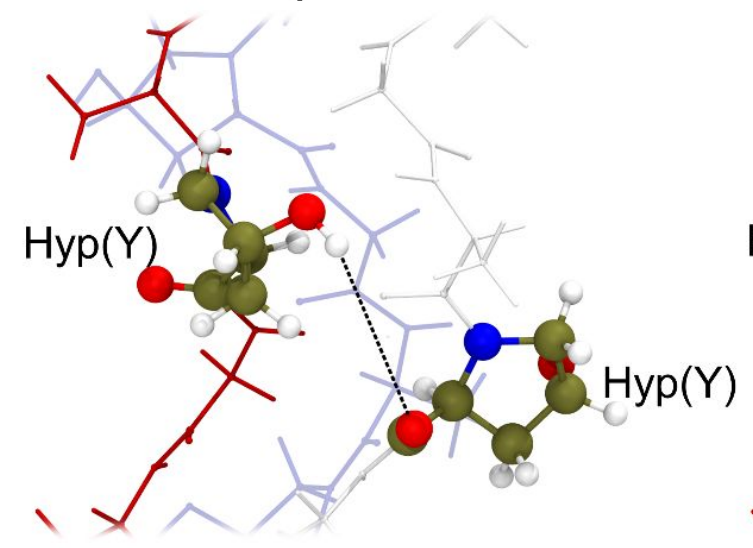

b)

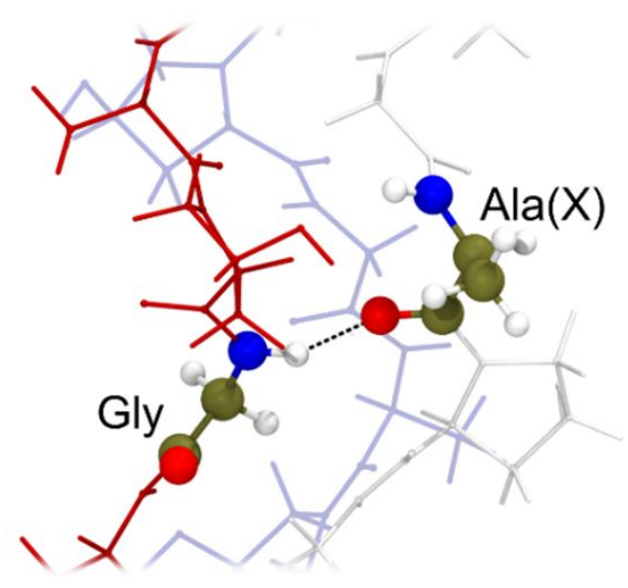

d)

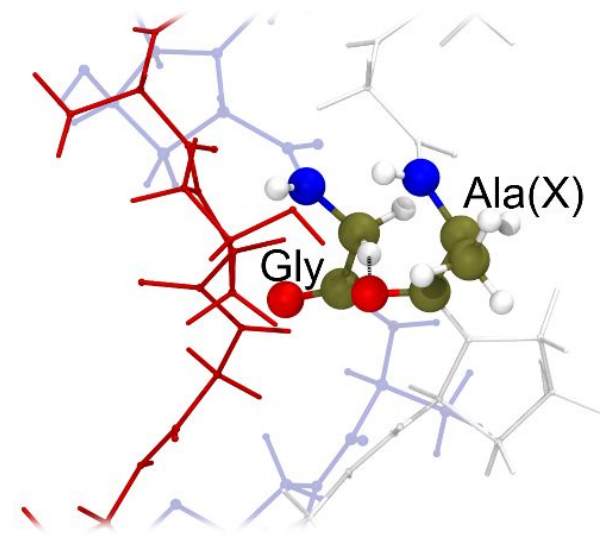

f)

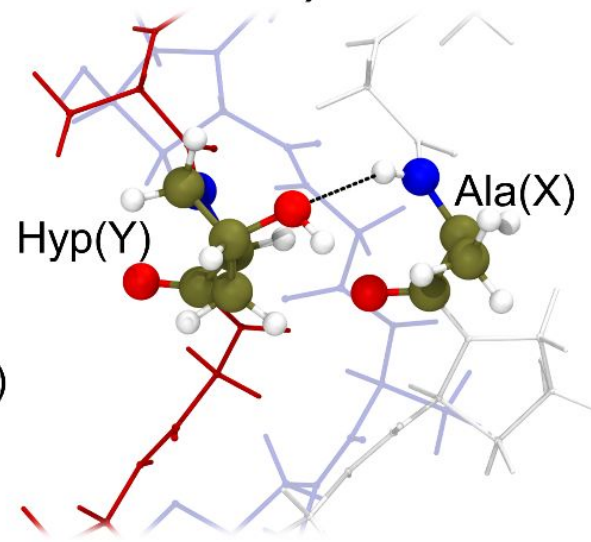




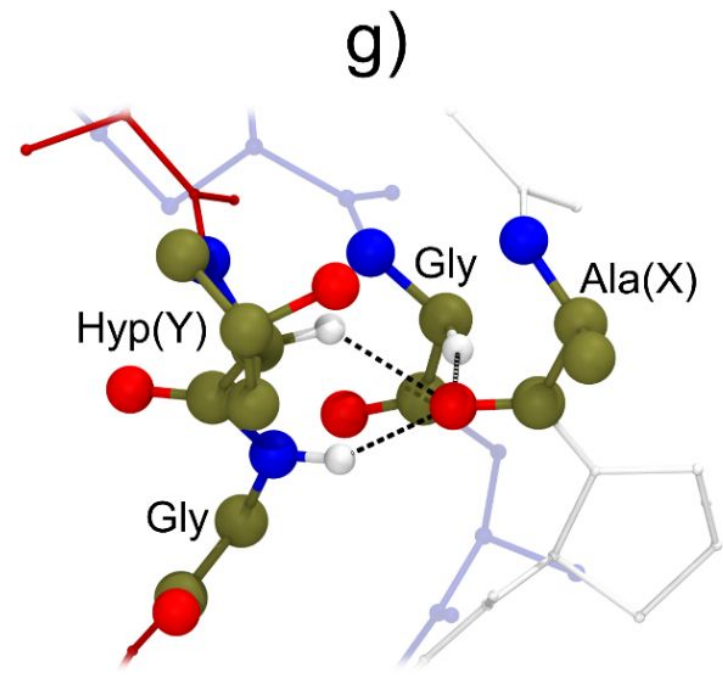

Figure S1. a) Torsional angles definition used in this work. b-g) Illustration of the interstrands electrostatic contacts $(E C)$ for the GAO case. The three independent collagen strands are coloured with different colours, and the chain in blue, being in background, is shaded. The atoms involved in the ECs are reported in ball and stick. Colour code: Oxygen in red, Hydrogen in white, Carbon in cyan and Nitrogen in blue. The dotted black line indicates the EC. b: The $\mathrm{H}$-bond between $\mathrm{N}-\mathrm{H}$ and $\mathrm{O}=\mathrm{C}$ belonging to Gly and $\mathrm{X}$ (EC1), respectively. c: Electrostatic contact between $\mathrm{C}=\mathrm{O}$ belonging to the $\mathrm{X}$ residue and $\mathrm{C}-\mathrm{H}$ to Hyp (EC2). d: Electrostatic contact between $\mathrm{C}=\mathrm{O}$ belonging to the $\mathrm{X}$ residue and $\mathrm{C}-\mathrm{H}$ to $\mathrm{Gly}$ (EC3). e: $\mathrm{O}-\mathrm{H} \cdots \mathrm{O}=\mathrm{C}$ contact between two Hyp (EC4). f: $\mathrm{N}-\mathrm{H} \cdots \mathrm{O}-\mathrm{H}$ contact between the residue in $X$ and Hyp (EC5). $\mathbf{g}$ : Summary of the three electrostatic contacts involving the $\mathrm{C}=\mathrm{O}$ group of the aminoacid in $\mathrm{X}$.

\section{Results and Discussion}

Table S5. Inter-chains contacts (EC1-5) for GGO-7/2 model obtained (by ions and cell relaxation) at the PBE-D2/QZP, PBE-D2/PW(500eV) and PBE-D2/PW(1000eV) levels. Units in $\AA$.

\begin{tabular}{ccccccc}
\hline \hline & EC1 & EC4 & EC5 & EC2 & EC3 & cell length \\
\hline PBE-D2/QZP & 2.432 & 2.190 & 3.046 & 1.974 & 2.470 & 20.22 \\
PBE-D2/PW(500eV) & 2.404 & 2.311 & 3.065 & 1.976 & 2.469 & 20.23 \\
PBE-D2/PW(1000eV) & 2.404 & 2.308 & 3.064 & 1.975 & 2.469 & 20.23 \\
\hline \hline
\end{tabular}



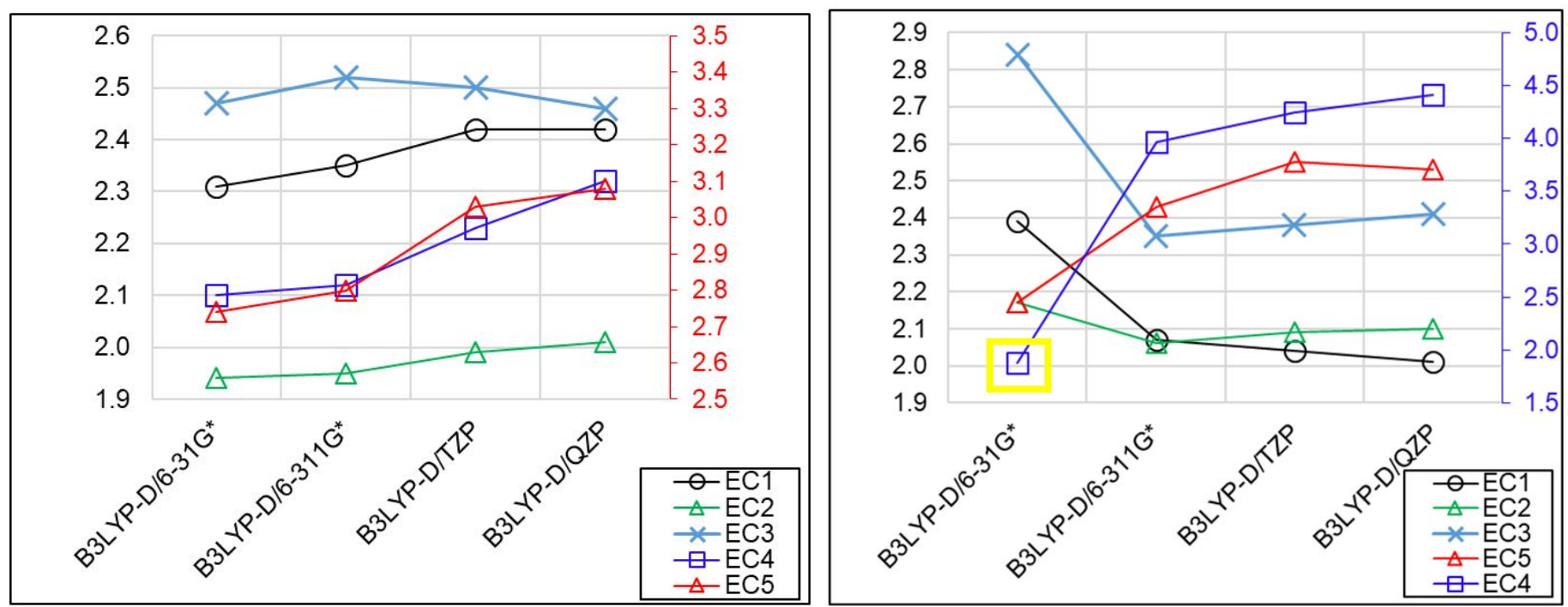

Figure S2 Effect of BS on the inter-chain contacts (EC1-5) between GGO COL strands. Distances in A. LEFT: 7/2 helix. The EC5 points are related to the secondary axis (on the right). RIGHT: 10/3 helix. The EC4 points are related to the secondary axis (on the right). The yellow-highlighted point at the B3LYP-D/6-31G* for the GGO-10/3 case indicates that the EC4 is not actually present in this model. In this case, the Hyp $\mathrm{OH}$ group interacts with the Gly $\mathrm{C}=\mathrm{O}$ group (X position) and not with the Hyp $\mathrm{C}=\mathrm{O}$ group ( $\mathrm{Y}$ position). The number reported in the graph indicate this distance. 

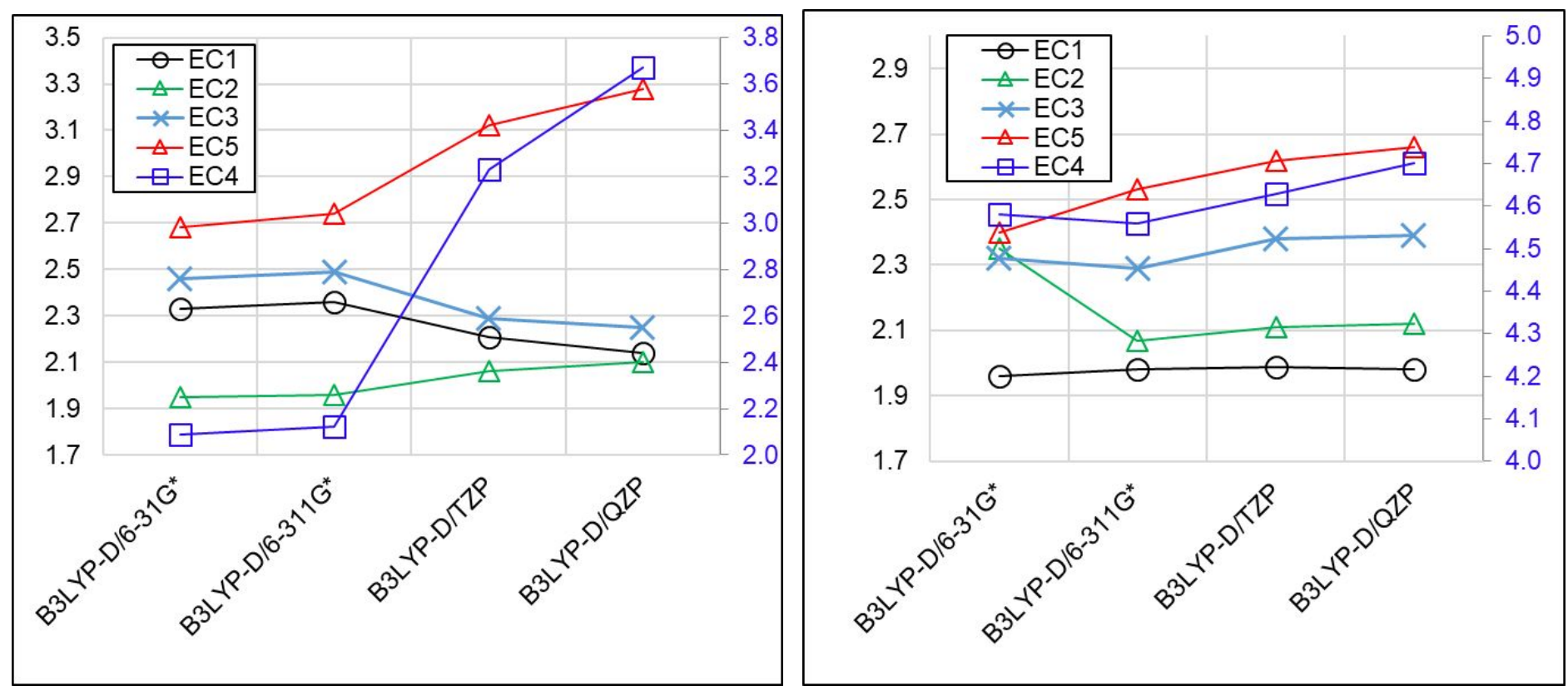

Figure S3. Effect of BS on the inter-chain contacts (EC1-5) between GAO COL strands. Distances in A. The EC4 points are related to the secondary axis (on the right). LEFT: 7/2 helix. RIGHT: 10/3 helix. 

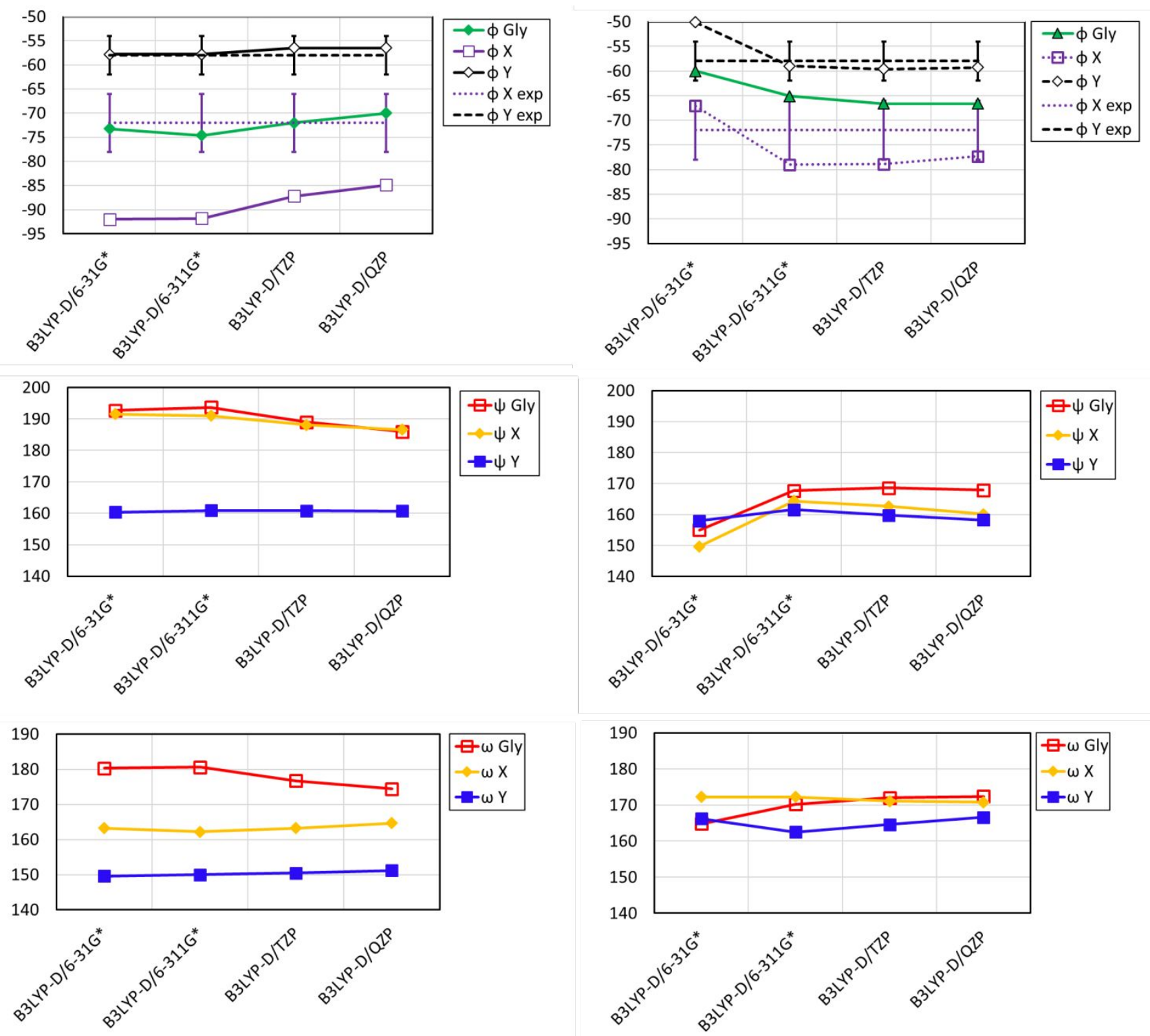

Figure S4. Effect of BS on the torsional angle of $X=G l y$ and $Y=H y p$ ( $G G O$ case) compared with the experimental value (and error bar) averaged on collagen peptide crystal structures at resolution $1.5 \AA$ or better. ${ }^{3}$ LEFT: $7 / 2$ helix RIGHT: $10 / 3$ helix. 

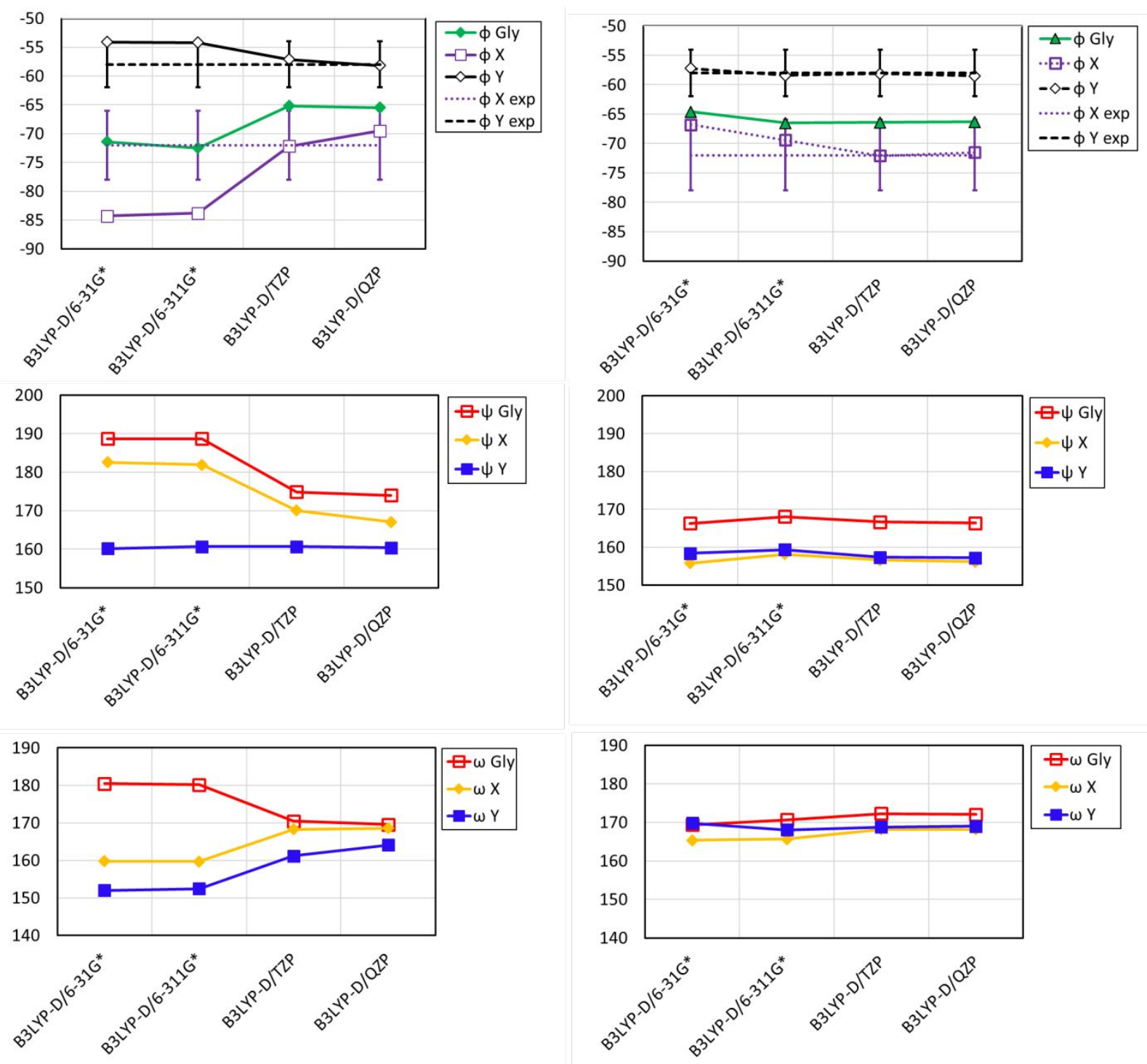

Figure S5. Effect of BS on the torsional angle of $X=A l a$ and $Y=H y p$ (GAO case) compared with the experimental value (and error bar) averaged on collagen peptide crystal structures at resolution $1.5 \AA$ or better. ${ }^{3}$ LEFT: $7 / 2$ helix RIGHT: $10 / 3$ helix. 

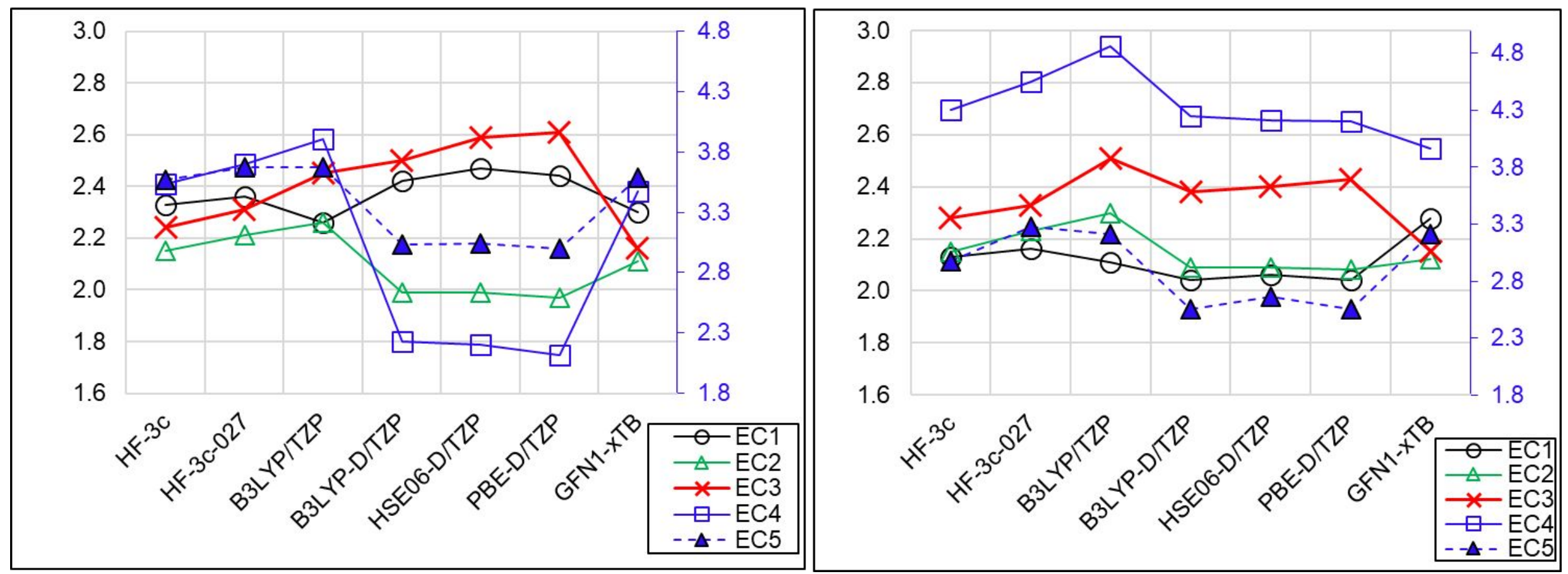

Figure S6. Effect of the method on the inter-chain contacts (EC1-5) between GGO strands. EC4-5 points are related to the secondary axis (on the right). $D=D 3^{A B C}$. Distances in $A$. LEFT: 7/2 helix. RIGHT: 10/3 helix. 


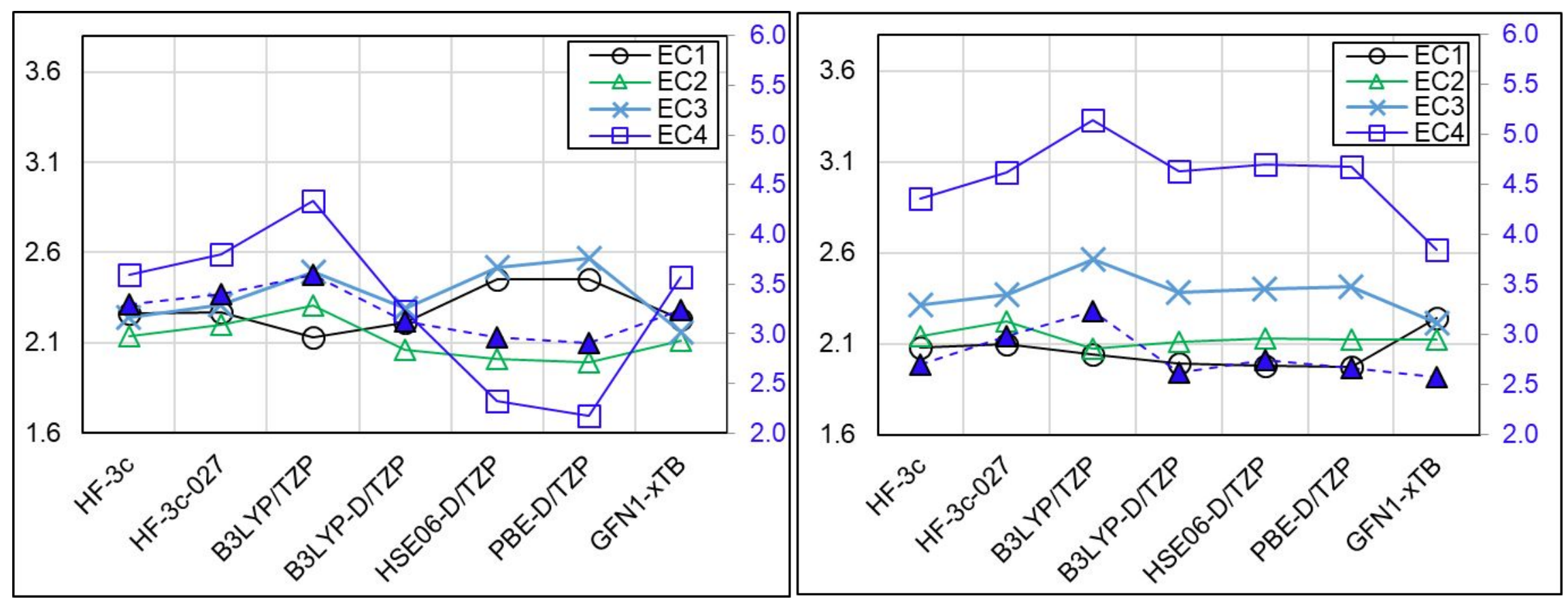

Figure S7. Effect of the method on the inter-chain contacts (EC1-5) between GAO strands. In both graphs, the EC4-5 points are related to the secondary axis (on the right). D = D3 ${ }^{A B C}$. Distances in $A$. LEFT: $7 / 2$ helix. RIGHT: 10/3 helix. 

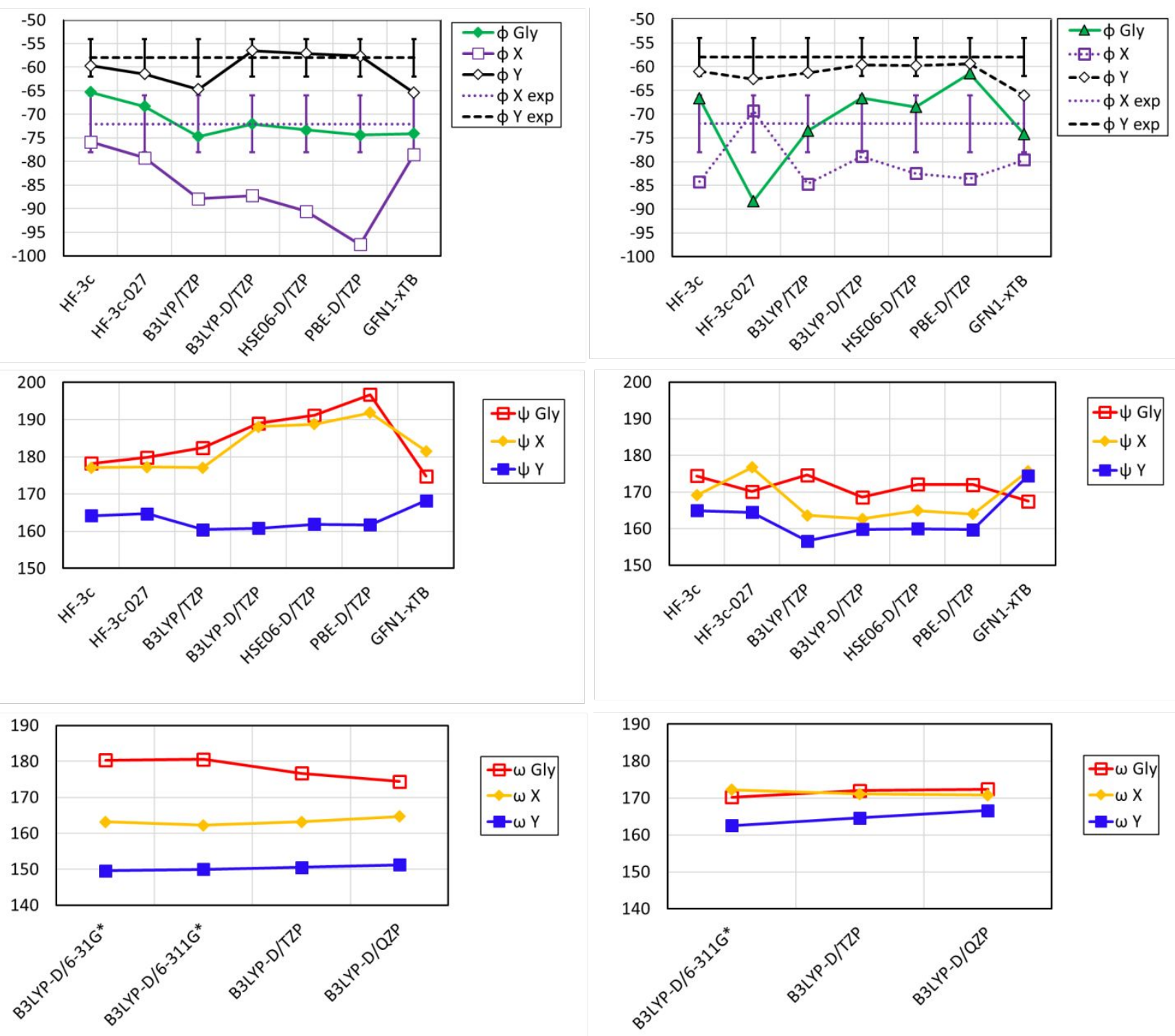

Figure S8. Effect of the method on the dihedral angles of GGO collagens along with the experimental value (and error bar) averaged on collagen peptide crystal structures at resolution $1.5 \AA$ or better. ${ }^{3}$ Distances in $\AA$. $D=D 3^{A B C}$. LEFT: $7 / 2$ helix. RIGHT: 10/3 helix. 

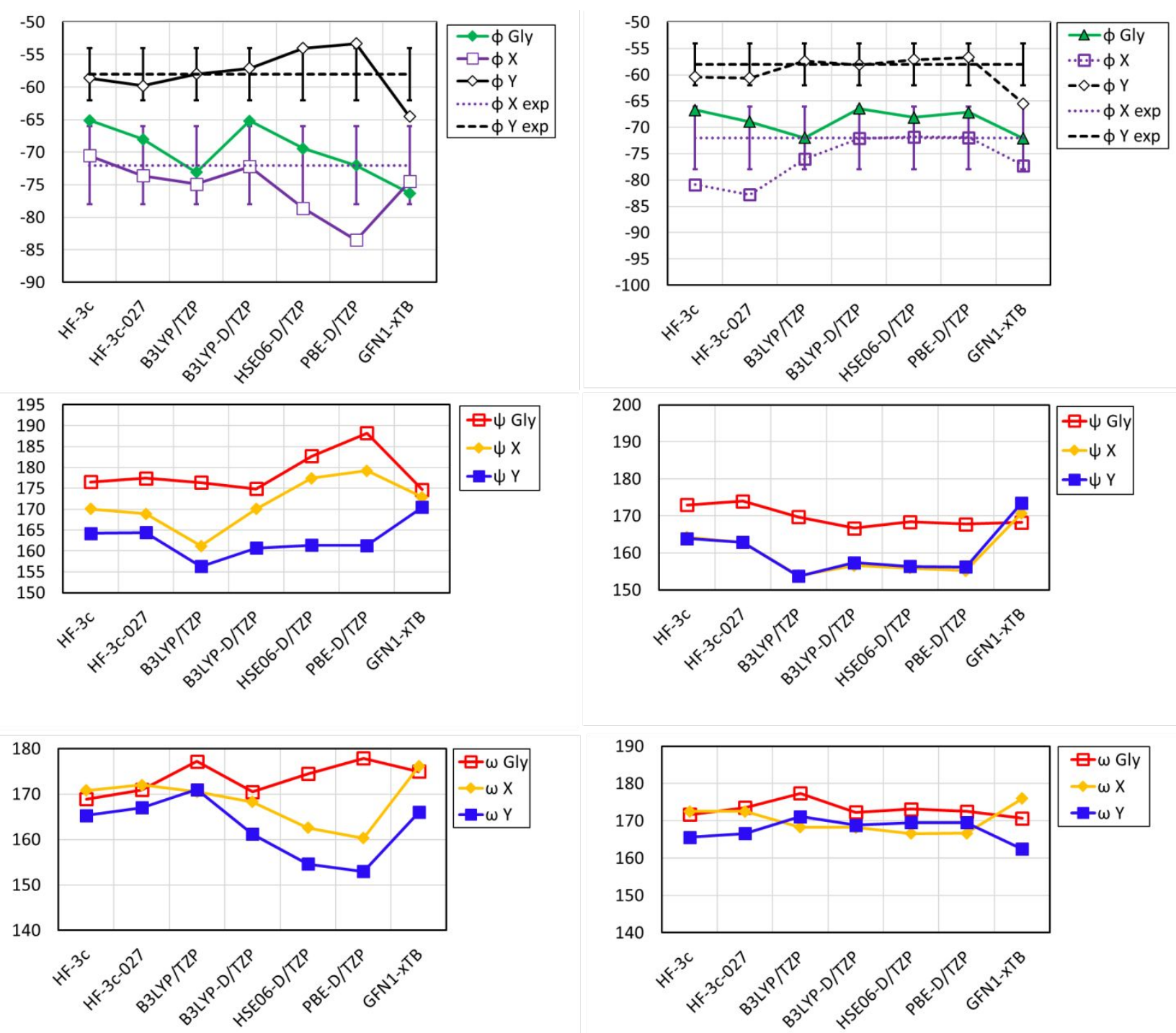

Figure S9. Effect of the method on the dihedral angles of GAO collagen along with the experimental value (and error bar) averaged on collagen peptide crystal structures at resolution $1.5 \AA$ or better. ${ }^{3}$ Distances in $\AA$. $D=D 3{ }^{A B C}$. LEFT: $7 / 2$ helix. RIGHT: 10/3 helix. 


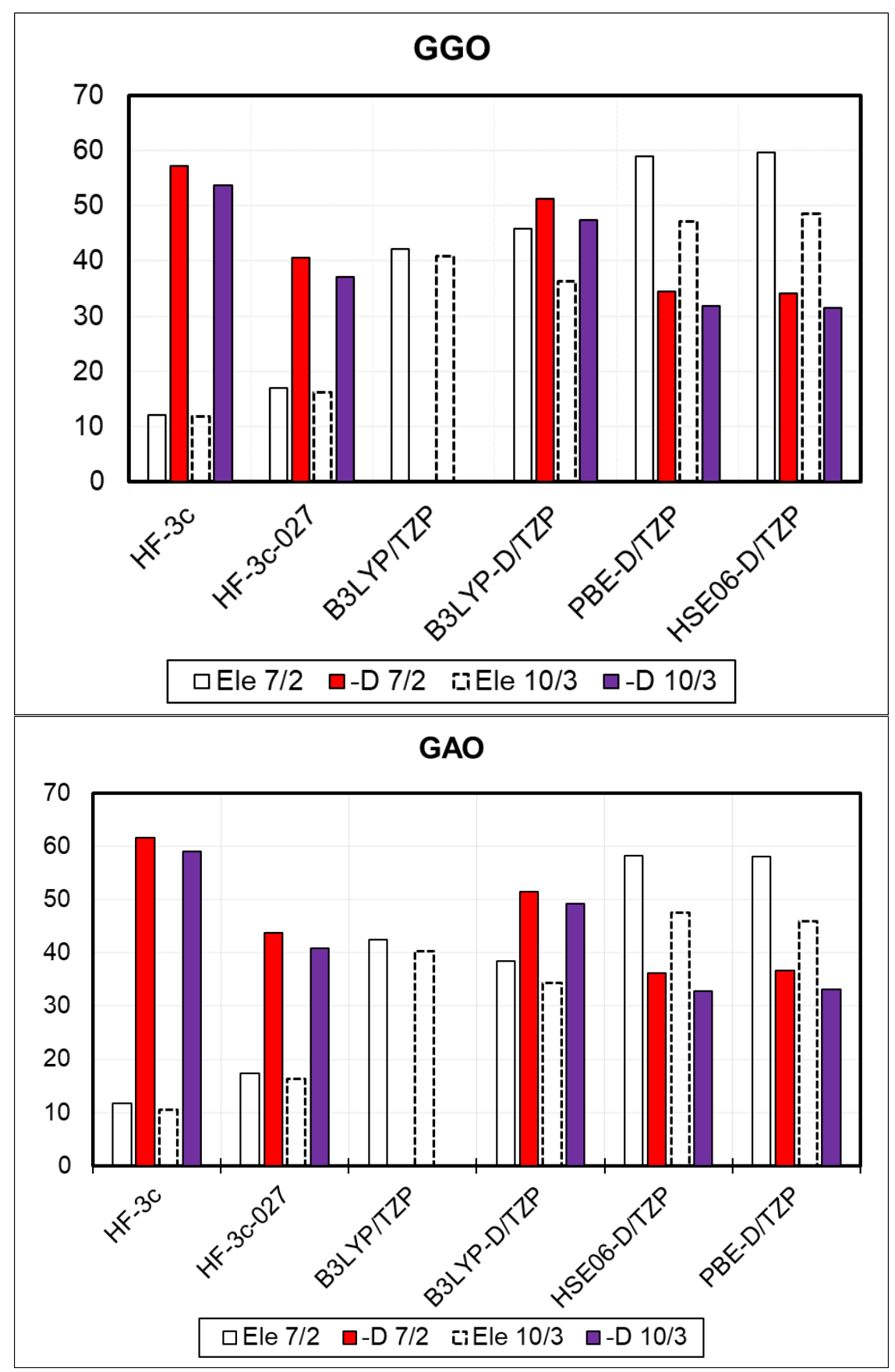

Figure S10. Effect of the method on the $\mathrm{BE}^{\star \mathrm{C}}$ (in kJ. $\mathrm{mol}^{-1}$. triplet $^{-1}$ ) of $\mathrm{GGO}$ and $\mathrm{GAO}$ collagen helices. Electrostatic and dispersive component are reported separated. $\mathrm{D}=\mathrm{D} 3^{\mathrm{ABC}}$. 


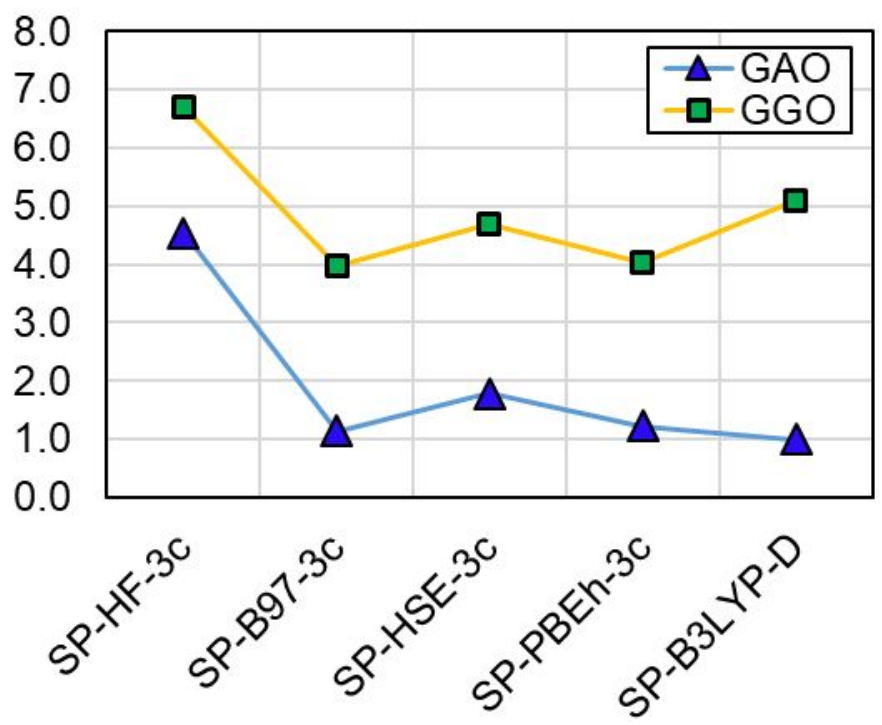

Figure S11. Effect on $\Delta \mathrm{E}$-helix using different functionals. Positive values of $\Delta \mathrm{E}$-helix indicate that a $7 / 2$ packing is preferred. Values in $\mathrm{KJ} \cdot \mathrm{mol}^{-1} \cdot \operatorname{triplet}^{-1}$. Geometries computed at the HF-3c-027 level of theory. 
Table S6. Geometry, e.g. dihedral angles and electrostatic contacts (see Figure S1 for definitions), of the GGO-7/2 and GGO-10/3 triple helices relaxed using different methods. The angles are expressed in degree, while the lengths are expressed in $\AA$. Standard deviation in brackets.

\begin{tabular}{|c|c|c|c|c|c|c|c|c|c|c|c|c|c|c|c|c|}
\hline \multirow{3}{*}{ METHOD } & \multicolumn{16}{|c|}{$7 / 2$ helix } \\
\hline & \multicolumn{3}{|c|}{ Gly } & \multicolumn{3}{|c|}{$\mathrm{X}$} & \multicolumn{3}{|c|}{$\mathrm{Y}$} & \multirow[b]{2}{*}{ EC1 } & \multirow[b]{2}{*}{ EC2 } & \multirow[b]{2}{*}{ EC3 } & \multirow[b]{2}{*}{ EC4 } & \multirow[b]{2}{*}{ EC5 } & \multirow[b]{2}{*}{$\begin{array}{l}\text { unit } \\
\text { cell }\end{array}$} & \multirow[b]{2}{*}{\begin{tabular}{|c} 
rise \\
per \\
triplet
\end{tabular}} \\
\hline & $\varphi$ & $\Psi$ & $\omega$ & $\varphi$ & $\psi$ & $\omega$ & $\varphi$ & $\psi$ & $\omega$ & & & & & & & \\
\hline HF-3c & -65 & 178 & 169 & -76 & 177 & 174 & -60 & 164 & 162 & 2.33 & 2.15 & 2.24 & 3.53 & 3.57 & 19.73 & 8.46 \\
\hline HF-3c-027 & -68 & 180 & 170 & -79 & 177 & 174 & -61 & 165 & 163 & 2.36 & 2.21 & 2.31 & 3.70 & 3.67 & 20.17 & 8.64 \\
\hline B3LYP/TZP & -75 & -178 & 178 & -88 & 177 & 176 & -65 & 160 & 163 & 2.26 & 2.26 & 2.45 & 3.91 & 3.67 & 21.09 & 9.04 \\
\hline B3LYP-D/6-31G* & -73 & -167 & -180 & -92 & -168 & 163 & -58 & 160 & 150 & 2.31 & 1.94 & 2.47 & 2.10 & 2.74 & 20.37 & 8.73 \\
\hline B3LYP-D/6-311G* & -75 & -166 & -179 & -92 & -169 & 162 & -58 & 161 & 150 & 2.35 & 1.95 & 2.52 & 2.12 & 2.80 & 20.42 & 8.75 \\
\hline B3LYP-D/TZP & -72 & -171 & 177 & -87 & -172 & 163 & -57 & 161 & 151 & 2.42 & 1.99 & 2.50 & 2.23 & 3.03 & 20.30 & 8.70 \\
\hline B3LYP-D/QZP & -70 & -174 & 174 & -85 & -173 & 165 & -57 & 161 & 151 & 2.42 & 2.01 & 2.46 & 2.32 & 3.08 & 20.23 & 8.67 \\
\hline HSE06-D/TZP & -73 & -169 & 177 & -91 & -171 & 165 & -57 & 162 & 151 & 2.47 & 1.99 & 2.59 & 2.20 & 3.04 & 20.32 & 8.71 \\
\hline PBE-D/TZP & -74 & -163 & 179 & -98 & -168 & 165 & -58 & 162 & 149 & 2.44 & 1.97 & 2.61 & 2.12 & 3.00 & 20.64 & 8.85 \\
\hline \multirow[t]{2}{*}{ GFN1-xTB } & $\begin{array}{l}-64.5 \\
(1.5)\end{array}$ & $\begin{array}{c}-176.3 \\
(0.9)\end{array}$ & \begin{tabular}{|l}
175.6 \\
$(0.4)$
\end{tabular} & $\begin{array}{c}-87.0 \\
(0.7)\end{array}$ & \begin{tabular}{|c|}
179.0 \\
$(0.7)$
\end{tabular} & $\begin{array}{c}178.8( \\
0.6)\end{array}$ & \begin{tabular}{|c|}
-56.6 \\
$(0.5)$
\end{tabular} & $\begin{array}{l}159.4 \\
(1.4)\end{array}$ & $\begin{array}{c}155.4 \\
(0.3)\end{array}$ & $\begin{array}{c}1.8 \\
(0.0)\end{array}$ & $\begin{array}{c}2.0 \\
(0.0)\end{array}$ & $\begin{array}{c}2.1 \\
(0.0)\end{array}$ & $\begin{array}{c}3.5 \\
(0.0)\end{array}$ & $\begin{array}{c}3.6 \\
(0.0)\end{array}$ & 20.034 & 8.59 \\
\hline & \multicolumn{16}{|c|}{$10 / 3$ helix } \\
\hline METHOD & \multicolumn{3}{|c|}{ Gly } & \multicolumn{3}{|c|}{$X$} & \multicolumn{3}{|c|}{$\mathrm{Y}$} & & & & & & & \\
\hline & $\varphi$ & $\Psi$ & $\omega$ & $\varphi$ & $\Psi$ & $\omega$ & $\varphi$ & $\psi$ & $\omega$ & EC1 & EC2 & EC3 & EC4 & EC5 & $\begin{array}{l}\text { unit } \\
\text { cell }\end{array}$ & \begin{tabular}{|c|} 
rise \\
per \\
triplet
\end{tabular} \\
\hline HF-3c & -67 & 174 & 170 & -84 & 169 & 174 & -61 & 165 & 162 & 2.13 & 2.15 & 2.28 & 4.30 & 2.97 & 29.47 & 8.84 \\
\hline HF-3c-027 & -88 & 170 & 175 & -69 & 177 & 172 & -63 & 165 & 163 & 2.16 & 2.23 & 2.33 & 4.55 & 3.28 & 30.11 & 9.03 \\
\hline B3LYP/TZP & -74 & 175 & 178 & -85 & 164 & 171 & -61 & 157 & 167 & 2.11 & 2.30 & 2.51 & 4.86 & 3.21 & 30.59 & 9.18 \\
\hline B3LYP-D/6-31G* & -60 & 155 & 165 & -67 & 150 & 172 & -50 & 158 & 166 & 2.39 & 2.17 & 2.84 & 1.88 & 2.17 & 28.66 & 8.60 \\
\hline B3LYP-D/6-311G* & -65 & 168 & 170 & -79 & 164 & 172 & -59 & 162 & 163 & 2.07 & 2.06 & 2.35 & 3.97 & 2.43 & 29.43 & 8.83 \\
\hline B3LYP-D/TZP & -67 & 169 & 172 & -79 & 163 & 171 & -60 & 160 & 165 & 2.04 & 2.09 & 2.38 & 4.25 & 2.55 & 29.66 & 8.90 \\
\hline B3LYP-D/QZP & -67 & 168 & 172 & -77 & 160 & 171 & -59 & 158 & 167 & 2.01 & 2.10 & 2.41 & 4.41 & 2.53 & 29.66 & 8.90 \\
\hline HSE06-D/TZP & -69 & 172 & 173 & -83 & 165 & 171 & -60 & 160 & 164 & 2.06 & 2.09 & 2.40 & 4.21 & 2.66 & 29.73 & 8.92 \\
\hline PBE-D/TZP & -61 & 172 & 174 & -84 & 164 & 171 & -59 & 160 & 164 & 2.04 & 2.08 & 2.43 & 4.20 & 2.55 & 30.03 & 9.01 \\
\hline
\end{tabular}


Table S7. BSSE corrected binding energy and BSSE correction for the GGO-7/2 and GGO-10/3 triple helices. Values are reported in $\mathrm{kJ} \cdot \mathrm{mol}^{-1} \cdot$ triplet $^{-1}$.

\begin{tabular}{|c|c|c|c|c|c|c|c|c|c|c|c|}
\hline & & \multicolumn{9}{|c|}{$\mathrm{BE}^{* \mathrm{C}}$} & \\
\hline & & $\mathrm{HF}-3 \mathrm{c}-027$ & $\mathrm{HF}-3 \mathrm{c}$ & $\begin{array}{l}\text { B3LYP } \\
\text { TZP }\end{array}$ & $\begin{array}{c}\text { B3LYP-D3 }{ }^{A B C} \\
6-31 G^{*}\end{array}$ & $\begin{array}{c}\text { B3LYP-D3 }{ }^{A B C} \\
6-311 G^{*}\end{array}$ & \multicolumn{2}{|c|}{$\begin{array}{c}\text { B3LYP-D3ABC } \\
\text { TZP }\end{array}$} & $\begin{array}{c}\text { B3LYP-D3ABC } \\
\text { QZP }\end{array}$ & $\begin{array}{c}\text { PBE-D3ABC } \\
\text { TZP }\end{array}$ & $\begin{array}{c}\text { HSE06-D3 }{ }^{A B C} \\
\text { TZP }\end{array}$ \\
\hline \multirow{3}{*}{$\begin{array}{l}\text { 7/2 single point on HF-3c-027 } \\
\text { geometry }\end{array}$} & $\mathrm{E}_{\text {tot }}$ & 57.5 & 67.3 & 34.6 & 75.0 & 76.7 & & & 76.7 & 72.8 & 75.8 \\
\hline & $E_{\text {bind }}$ & 17.0 & 17.0 & 34.6 & 32.3 & 33.9 & & & 33.9 & 42.7 & 45.7 \\
\hline & $E_{\text {disp }}$ & 40.5 & 50.3 & 0.0 & 42.8 & 42.8 & 42 & & 42.8 & 30.1 & 30.1 \\
\hline \multirow{3}{*}{$7 / 2$ full optimization } & $E_{\text {tot }}$ & & 69.3 & 42.1 & 100.3 & 101.3 & 97 & & 94.6 & 93.4 & 93.8 \\
\hline & $E_{\text {bind }}$ & & 12.1 & 42.1 & 43.6 & 46.3 & 45 & & 44.2 & 58.9 & 59.6 \\
\hline & $E_{\text {disp }}$ & & 57.1 & 0.0 & 56.7 & 55.0 & 5 & & 50.3 & 34.5 & 34.2 \\
\hline \multirow{3}{*}{$\begin{array}{c}\text { 10/3 single point on HF-3c-027 } \\
\text { geometry }\end{array}$} & $E_{\text {tot }}$ & 53.4 & 62.2 & 32.6 & 70.0 & 71.6 & & & 71.3 & 68.2 & 71.0 \\
\hline & $E_{\text {bind }}$ & 16.3 & 16.3 & 32.6 & 30.7 & 32.3 & 32 & & 31.9 & 40.3 & 42.9 \\
\hline & $E_{\text {disp }}$ & 37.1 & 45.8 & 0.0 & 39.4 & 39.4 & 35 & & 39.4 & 27.9 & 28.1 \\
\hline \multirow{6}{*}{ 10/3 full optimization } & $E_{\text {tot }}$ & & 65.5 & 40.9 & 102.7 & 85.5 & & & 83.3 & 79.0 & 80.1 \\
\hline & $\mathrm{E}_{\mathrm{bind}}$ & & 11.9 & 40.9 & 49.4 & 34.8 & & & 36.7 & 47.2 & 48.6 \\
\hline & $E_{\text {disp }}$ & & 53.7 & 0.0 & 53.3 & 50.7 & & & 46.6 & 31.8 & 31.5 \\
\hline & & \multicolumn{10}{|c|}{ BSSE } \\
\hline & & \multirow{2}{*}{\multicolumn{2}{|c|}{$\begin{array}{c}\text { B3LYP/ } \\
\text { TZP }\end{array}$}} & 3LYP-D3ABC/ & \multirow{2}{*}{\multicolumn{2}{|c|}{$\begin{array}{c}\text { B3LYP-D3 }{ }^{A B C /} \\
6-311 G^{*}\end{array}$}} & & \multirow{2}{*}{\multicolumn{2}{|c|}{$\begin{array}{c}\text { B3LYP-D3ABC/ } \\
\text { QZP }\end{array}$}} & $\mathrm{BE}-\mathrm{D} 3^{\mathrm{ABC}} /$ & HSE06-D3ABC/ \\
\hline & & & & $6-31 G^{*}$ & & & & & & TZP & TZP \\
\hline \multicolumn{2}{|c|}{$7 / 2$ single point on HF-3c-027 geometry } & 5.3 & & 26.0 & 18.8 & \multicolumn{2}{|c|}{5.3} & \multicolumn{2}{|r|}{2.7} & 6.2 & 5.2 \\
\hline \multicolumn{2}{|l|}{ 7/2 full optimization } & 5.0 & & 36.2 & \multirow{2}{*}{$\begin{array}{l}25.3 \\
18.9\end{array}$} & \multicolumn{2}{|c|}{6.5} & \multicolumn{2}{|r|}{3.3} & 7.5 & 6.2 \\
\hline \multicolumn{2}{|c|}{$10 / 3$ single point on HF-3c- 027 geometry } & 5.1 & & 26.1 & & \multicolumn{2}{|c|}{5.1} & & 2.5 & 6.0 & 4.9 \\
\hline 10/3 full optimization & & 5.1 & & 36.9 & $\begin{array}{l}18.9 \\
23.6\end{array}$ & 6 & 3 & & 3.3 & 7.1 & 5.8 \\
\hline
\end{tabular}


Table S8. Evaluation of the energy differences ( $\triangle \mathrm{E}$-helix) and contributions $\left(\Delta \mathrm{BE}^{*}\right.$ and $\Delta \mathrm{E}-$ ss, with $\Delta \mathrm{E}$-helix $=-\Delta \mathrm{BE}^{*}+\Delta \mathrm{E}$-ss) between the $7 / 2$ and $10 / 3$ conformations of the GGO triple helix with different computational methods. All the results are expressed in $\mathrm{kJ} \mathrm{mol}^{-}$ 1. triplet $^{-1}$.

\begin{tabular}{|c|c|c|c|c|c|}
\hline & & $-\Delta \mathrm{BE}^{*}$ & $\Delta \overline{\mathrm{E}}$-helix & $\Delta \overline{\mathrm{E}}$-ss & $\triangle \mathrm{ABSSE}$ \\
\hline & $E_{\text {tot }}$ & 4.1 & 5.3 & 1.2 & 0.0 \\
\hline \multirow[t]{2}{*}{ HF-3c-027//HF-3c-027 } & $\mathrm{E}_{\mathrm{el}}$ & 0.7 & 0.9 & 0.3 & 0.0 \\
\hline & $E_{\text {disp }}$ & 3.4 & 4.3 & 0.9 & 0.0 \\
\hline \multirow{3}{*}{$\mathrm{HF}-3 \mathrm{c} / / \mathrm{HF}-3 \mathrm{c}-027$} & $\mathrm{E}_{\text {tot }}$ & 5.1 & 6.7 & 1.6 & 0.0 \\
\hline & $\mathrm{E}_{\mathrm{el}}$ & 0.7 & 0.9 & 0.3 & 0.0 \\
\hline & $E_{\text {disp }}$ & 4.4 & 5.7 & 1.3 & 0.0 \\
\hline \multirow{3}{*}{$\mathrm{HF}-3 \mathrm{c} / / \mathrm{HF}-3 \mathrm{c}$} & $E_{\text {tot }}$ & 3.7 & 6.4 & 2.7 & 0.0 \\
\hline & $\mathrm{E}_{\mathrm{el}}$ & 0.3 & 1.3 & 1.0 & 0.0 \\
\hline & $E_{\text {disp }}$ & 3.5 & 5.1 & 1.6 & 0.0 \\
\hline \multirow{2}{*}{ B3LYP/TZP//B3LYP/TZP } & $E_{\text {tot }}$ & 1.2 & 1.0 & -0.2 & 0.0 \\
\hline & $\mathrm{E}_{\mathrm{el}}$ & 1.2 & 1.0 & -0.2 & 0.0 \\
\hline \multirow{3}{*}{ B3LYP-D3ABC/6-31G*//HF-3c-027 } & $E_{\text {tot }}$ & 5.0 & 4.9 & -0.1 & 0.1 \\
\hline & $\mathrm{E}_{\mathrm{el}}$ & 1.6 & 0.7 & -0.9 & 0.1 \\
\hline & $E_{\text {disp }}$ & 3.4 & 4.2 & 0.8 & 0.0 \\
\hline \multirow{3}{*}{ B3LYP-D3 ${ }^{A B C} / 6-31 G^{*} / / B 3 L Y P-D 3{ }^{A B C} / 6-31 G^{*}$} & $E_{\text {tot }}$ & -3.1 & 3.4 & 6.5 & 0.6 \\
\hline & $\mathrm{E}_{\mathrm{el}}$ & -6.5 & 1.4 & 7.9 & 0.6 \\
\hline & $E_{\text {disp }}$ & 3.4 & 2.1 & -1.3 & 0.0 \\
\hline \multirow{3}{*}{ B3LYP-D3ABC/6-311G*//HF-3c-027 } & $\mathrm{E}_{\text {tot }}$ & -4.9 & 4.6 & -0.3 & 0.1 \\
\hline & $\mathrm{E}_{\mathrm{el}}$ & -1.5 & 0.4 & -1.1 & 0.1 \\
\hline & $E_{\text {disp }}$ & -3.4 & 4.2 & 0.8 & 0.0 \\
\hline \multirow{3}{*}{ B3LYP-D3ABC/6-311G*//B3LYP-D3ABC/6-311G* } & $E_{\text {tot }}$ & 17.4 & 6.9 & -10.5 & -1.6 \\
\hline & $\mathrm{E}_{\mathrm{el}}$ & 13.1 & 1.8 & -11.4 & -1.6 \\
\hline & $E_{\text {disp }}$ & 4.3 & 5.2 & 0.9 & 0.0 \\
\hline \multirow{3}{*}{ B3LYP-D3ABC/TZP//HF-3c-027 } & $\mathrm{E}_{\text {tot }}$ & 5.7 & 5.1 & -0.6 & -0.3 \\
\hline & $\mathrm{E}_{\mathrm{el}}$ & 2.3 & 0.9 & -1.4 & -0.3 \\
\hline & $E_{\text {disp }}$ & 3.4 & 4.2 & 0.8 & 0.0 \\
\hline \multirow{3}{*}{ B3LYP-D3ABC/TZP//B3LYP-D3 ${ }^{A B C} / T Z P$} & $E_{\text {tot }}$ & 13.7 & 4.9 & -8.7 & -0.2 \\
\hline & $\mathrm{E}_{\mathrm{el}}$ & 9.8 & -0.8 & -10.7 & -0.2 \\
\hline & $E_{\text {disp }}$ & 3.8 & 5.8 & 1.9 & 0.0 \\
\hline \multirow{3}{*}{ B3LYP-D3ABC/QZP//HF-3c-027 } & $E_{\text {tot }}$ & 5.6 & 4.9 & -0.8 & -0.2 \\
\hline & $\mathrm{E}_{\mathrm{el}}$ & 2.2 & 0.7 & -1.6 & -0.2 \\
\hline & $E_{\text {disp }}$ & 3.4 & 4.2 & 0.8 & 0.0 \\
\hline \multirow{3}{*}{ B3LYP-D3ABC/QZP//B3LYP-D3ABC/QZP } & $E_{\text {tot }}$ & 11.2 & 4.3 & -6.9 & 0.0 \\
\hline & $\mathrm{E}_{\mathrm{el}}$ & 7.5 & -1.6 & -9.1 & 0.0 \\
\hline & $E_{\text {disp }}$ & 3.7 & 6.0 & 2.2 & 0.0 \\
\hline \multirow{3}{*}{ PBE-D3ABC/TZP//HF-3c-027 } & $E_{\text {tot }}$ & 4.8 & 4.1 & -0.8 & -0.2 \\
\hline & $\mathrm{E}_{\mathrm{el}}$ & 2.6 & 1.4 & -1.2 & -0.2 \\
\hline & $E_{\text {disp }}$ & 2.2 & 2.7 & 0.5 & 0.0 \\
\hline \multirow{3}{*}{ PBE-D3ABC/TZP//PBE-D3ABC/TZP } & $E_{\text {tot }}$ & 14.7 & 5.9 & -8.8 & -0.3 \\
\hline & $\mathrm{E}_{\mathrm{el}}$ & 12.0 & 2.1 & -9.9 & -0.3 \\
\hline & $E_{\text {disp }}$ & 2.6 & 3.8 & 1.1 & 0.0 \\
\hline \multirow{3}{*}{ HSE06-D3ABC/TZP//HF-3c-027 } & $\mathrm{E}_{\text {tot }}$ & 5.0 & 4.2 & -0.8 & -0.3 \\
\hline & $\mathrm{E}_{\mathrm{el}}$ & 3.1 & 2.0 & -1.1 & -0.3 \\
\hline & $E_{\text {disp }}$ & 2.0 & 2.3 & 0.3 & 0.0 \\
\hline \multirow{3}{*}{ HSE06-D3ABC/TZP//HSE06-D3 ${ }^{A B C} / T Z P$} & $E_{\text {tot }}$ & 14.1 & 5.0 & -9.0 & -0.4 \\
\hline & $\mathrm{E}_{\mathrm{el}}$ & 11.4 & 1.7 & -9.7 & -0.4 \\
\hline & $E_{\text {disp }}$ & 2.7 & 3.3 & 0.7 & 0.0 \\
\hline
\end{tabular}


Table S9. Geometry, e.g. dihedral angles and electrostatic contacts (see Figure S1 for definitions), of the GAO-7/2 and GAO-10/3 triple helices relaxed using different methods. The angles are expressed in degree, while the lengths are expressed in $\AA$. Standard deviation in brackets.

\begin{tabular}{|c|c|c|c|c|c|c|c|c|c|c|c|c|c|c|c|c|}
\hline \multirow{3}{*}{ METHOD } & \multicolumn{16}{|c|}{$7 / 2$ helix } \\
\hline & \multicolumn{3}{|c|}{ Gly } & \multicolumn{3}{|c|}{$\mathrm{X}$} & \multicolumn{3}{|c|}{$\mathrm{Y}$} & \multirow[b]{2}{*}{ EC1 } & \multirow[b]{2}{*}{ EC2 } & \multirow[b]{2}{*}{ EC3 } & \multirow[b]{2}{*}{ EC4 } & \multirow[b]{2}{*}{ EC5 } & \multirow[b]{2}{*}{$\begin{array}{l}\text { unit } \\
\text { cell }\end{array}$} & \multirow[b]{2}{*}{$\begin{array}{c}\text { rise } \\
\text { per } \\
\text { triple }\end{array}$} \\
\hline & $\varphi$ & $\Psi$ & $\omega$ & $\varphi$ & $\psi$ & $\omega$ & $\varphi$ & $\psi$ & $\omega$ & & & & & & & \\
\hline HF-3c & -65 & 177 & 169 & -71 & 170 & 171 & -59 & 164 & 165 & 2.26 & 2.14 & 2.24 & 3.59 & 3.30 & 19.55 & 8.38 \\
\hline HF-3c-027 & -68 & 177 & 171 & -74 & 169 & 172 & -60 & 164 & 167 & 2.27 & 2.20 & 2.31 & 3.80 & 3.40 & 19.98 & 8.56 \\
\hline B3LYP/TZP & -73 & 176 & 177 & -75 & 161 & 171 & -58 & 156 & 171 & 2.13 & 2.31 & 2.49 & 4.34 & 3.60 & 20.64 & 8.85 \\
\hline B3LYP-D/6-31G* & -71 & -171 & -180 & -84 & -177 & 160 & -54 & 160 & 152 & 2.33 & 1.95 & 2.46 & 2.09 & 2.68 & 20.10 & 8.61 \\
\hline B3LYP-D/6-311G* & -73 & -171 & -180 & -84 & -178 & 160 & -54 & 161 & 153 & 2.36 & 1.96 & 2.49 & 2.12 & 2.74 & 20.16 & 8.64 \\
\hline B3LYP-D/TZP & -65 & 175 & 171 & -72 & 170 & 168 & -57 & 161 & 161 & 2.21 & 2.06 & 2.29 & 3.23 & 3.12 & 19.94 & 8.55 \\
\hline B3LYP-D/QZP & -66 & 174 & 170 & -70 & 167 & 169 & -58 & 160 & 164 & 2.14 & 2.10 & 2.25 & 3.67 & 3.28 & 19.95 & 8.55 \\
\hline HSE06-D/TZP & -69 & -177 & 175 & -79 & 177 & 163 & -54 & 161 & 155 & 2.45 & 2.01 & 2.52 & 2.32 & 2.97 & 19.94 & 8.55 \\
\hline PBE-D/TZP & -72 & -172 & 178 & -84 & 179 & 160 & -53 & 161 & 153 & 2.45 & 1.99 & 2.57 & 2.18 & 2.91 & 20.24 & 8.67 \\
\hline \multirow[t]{2}{*}{ GFN1-xTB } & \begin{tabular}{|l|}
-62.5 \\
$(7.2)$ \\
\end{tabular} & $\begin{array}{l}178.6 \\
(5.0) \\
\end{array}$ & $\begin{array}{l}175.9 \\
(2.7) \\
\end{array}$ & \begin{tabular}{|l|}
-82.8 \\
$(4.0)$
\end{tabular} & $\begin{array}{l}169.6 \\
(2.0) \\
\end{array}$ & \begin{tabular}{|l|}
-179.9 \\
$(2.0)$
\end{tabular} & \begin{tabular}{|l|}
-62.2 \\
$(3.3)$ \\
\end{tabular} & \begin{tabular}{|l}
162.5 \\
$(7.2)$
\end{tabular} & $\begin{array}{l}168.6 \\
(3.3)\end{array}$ & \begin{tabular}{|l|}
1.8 \\
$(0.1)$
\end{tabular} & \begin{tabular}{|l|}
2.2 \\
$(0.3)$ \\
\end{tabular} & \begin{tabular}{|l|}
2.1 \\
$(0.0)$
\end{tabular} & $\begin{array}{l}3.7 \\
(0.2) \\
\end{array}$ & \begin{tabular}{|l|}
2.3 \\
$(0.3)$ \\
\end{tabular} & 20.050 & 8.59 \\
\hline & \multicolumn{16}{|c|}{ 10/3 helix } \\
\hline METHOD & \multicolumn{3}{|c|}{ Gly } & \multicolumn{3}{|c|}{$X$} & \multicolumn{3}{|c|}{$\mathrm{Y}$} & & & & & & & \\
\hline & $\varphi$ & $\psi$ & $\omega$ & $\varphi$ & $\psi$ & $\omega$ & $\varphi$ & $\psi$ & $\omega$ & EC1 & EC2 & EC3 & EC4 & EC5 & $\begin{array}{l}\text { unit } \\
\text { cell }\end{array}$ & \begin{tabular}{|c|} 
rise \\
per \\
triplet
\end{tabular} \\
\hline $\mathrm{HF}-3 \mathrm{c}$ & -67 & 173 & 172 & -81 & 164 & 173 & -60 & 164 & 166 & 2.08 & 2.14 & 2.31 & 4.36 & 2.70 & 29.33 & 8.80 \\
\hline HF-3c-027 & -69 & 174 & 174 & -83 & 163 & 173 & -61 & 163 & 167 & 2.10 & 2.22 & 2.37 & 4.62 & 2.98 & 29.82 & 8.95 \\
\hline B3LYP/TZP & -72 & 170 & 177 & -76 & 154 & 168 & -57 & 154 & 171 & 2.04 & 2.07 & 2.56 & 5.14 & 3.23 & 30.10 & 9.03 \\
\hline B3LYP-D/6-31G* & -65 & 166 & 169 & -67 & 156 & 165 & -57 & 158 & 170 & 1.96 & 2.35 & 2.32 & 4.58 & 2.40 & 28.70 & 8.61 \\
\hline B3LYP-D/6-311G* & -67 & 168 & 171 & -69 & 158 & 166 & -58 & 159 & 168 & 1.98 & 2.07 & 2.29 & 4.56 & 2.53 & 29.00 & 8.70 \\
\hline B3LYP-D/TZP & -66 & 167 & 172 & -72 & 157 & 168 & -58 & 157 & 169 & 1.99 & 2.11 & 2.38 & 4.63 & 2.62 & 29.29 & 8.79 \\
\hline B3LYP-D/QZP & -66 & 166 & 172 & -72 & 156 & 168 & -59 & 157 & 169 & 1.98 & 2.12 & 2.39 & 4.70 & 2.66 & 29.34 & 8.80 \\
\hline HSE06-D/TZP & -68 & 168 & 173 & -72 & 156 & 167 & -57 & 156 & 170 & 1.98 & 2.13 & 2.40 & 4.70 & 2.74 & 29.17 & 8.75 \\
\hline
\end{tabular}




\begin{tabular}{|r|l|l|l|l|l|l|l|l|l|l|l|l|l|l|l|l|} 
PBE-D/TZP & -67 & 168 & 173 & -72 & 155 & 167 & -57 & 156 & 170 & 1.97 & 2.12 & 2.41 & 4.68 & 2.66 & 29.38 & 8.81 \\
\hline \multirow{2}{*}{ GFN1-xTB } & -64.3 & -64.3 & -64.3 & -64.3 & -64.3 & -64.3 & -64.3 & -64.3 & -64.3 & -64.3 & -64.3 & -64.3 & -64.3 & -64.3 & 28.830 & 8.65 \\
& $(7.6)$ & $(7.6)$ & $(7.6)$ & $(7.6)$ & $(7.6)$ & $(7.6)$ & $(7.6)$ & $(7.6)$ & $(7.6)$ & $(7.6)$ & $(7.6)$ & $(7.6)$ & $(7.6)$ & $(7.6)$ & & \\
\end{tabular}


Table S10. BSSE corrected binding energy and BSSE corrections for the GAO-7/2 and GAO-10/3 triple helices. Values are reported in $\mathrm{kJ} \cdot \mathrm{mol}^{-1}$. triplet $^{-1}$.

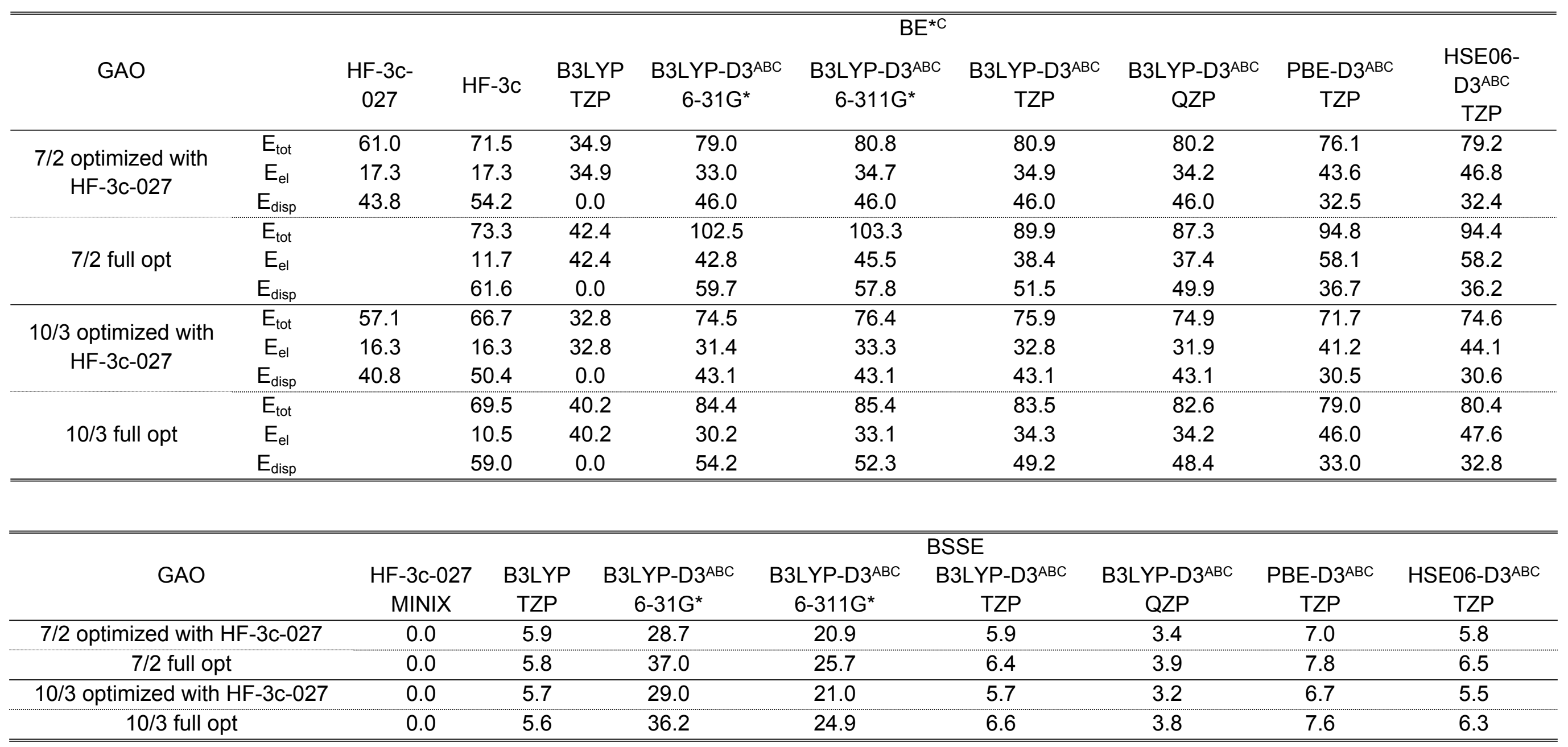


Table S11. Evaluation of the energy differences ( $\triangle \mathrm{E}$-helix) and contributions ( $\triangle \mathrm{BE}^{*}$ and $\triangle \mathrm{E}-$ ss, with $\Delta \mathrm{E}$-helix $=-\Delta \mathrm{BE}^{*}+\Delta \mathrm{E}$-ss) between the $7 / 2$ and $10 / 3$ conformations of the GAO triple helix with different computational methods. All the results are expressed in $\mathrm{kJ} \mathrm{mol}^{-}$ 1. triplet $^{-1}$.

\begin{tabular}{|c|c|c|c|c|c|}
\hline & & $-\Delta \mathrm{BE}^{*}$ & $\Delta \mathrm{E}$ E-helix & $\Delta \mathrm{E}$ E-ss & $\triangle \mathrm{BSSE}$ \\
\hline \multirow{3}{*}{ HF-3c-027//HF-3c-027 } & $E_{\text {tot }}$ & 4.0 & 3.1 & -0.8 & 0.0 \\
\hline & $\mathrm{E}_{\mathrm{el}}$ & 1.0 & -1.1 & -2.1 & 0.0 \\
\hline & $E_{\text {disp }}$ & 3.0 & 4.2 & 1.3 & 0.0 \\
\hline \multirow{3}{*}{ HF-3c//HF-3c-027 } & $\mathrm{E}_{\text {tot }}$ & 4.8 & 4.5 & -0.2 & 0.0 \\
\hline & $\mathrm{E}_{\mathrm{el}}$ & 1.0 & -1.1 & -2.1 & 0.0 \\
\hline & $E_{\text {disp }}$ & 3.8 & 5.6 & 1.8 & 0.0 \\
\hline \multirow{3}{*}{$\mathrm{HF}-3 \mathrm{c} / / \mathrm{HF}-3 \mathrm{c}$} & $E_{\text {tot }}$ & 3.8 & 4.3 & 0.5 & 0.0 \\
\hline & $\mathrm{E}_{\mathrm{el}}$ & 1.2 & -0.8 & -2.1 & 0.0 \\
\hline & $E_{\text {disp }}$ & 2.6 & 5.2 & 2.6 & 0.0 \\
\hline \multirow{2}{*}{ B3LYP/TZP//B3LYP/TZP } & $\mathrm{E}_{\text {tot }}$ & 2.4 & -1.9 & -4.2 & -0.2 \\
\hline & $E_{e l}$ & 2.4 & -1.9 & -4.2 & -0.2 \\
\hline \multirow{3}{*}{ B3LYP-D3ABC/6-31G*//HF-3c-027 } & $\mathrm{E}_{\text {tot }}$ & 4.4 & 1.7 & -2.6 & 0.2 \\
\hline & $\mathrm{E}_{\mathrm{el}}$ & 1.4 & -2.1 & -3.5 & 0.2 \\
\hline & $E_{\text {disp }}$ & 3.0 & 3.8 & 0.9 & 0.0 \\
\hline \multirow{3}{*}{ B3LYP-D3 ${ }^{A B C} / 6-31 G^{*} / / B 3 L Y P-D 3{ }^{A B C} / 6-31 G^{*}$} & $E_{\text {tot }}$ & 19.0 & 4.5 & -14.5 & -0.8 \\
\hline & $\mathrm{E}_{\mathrm{el}}$ & 13.4 & -2.5 & -15.9 & -0.8 \\
\hline & $E_{\text {disp }}$ & 5.6 & 7.1 & 1.5 & 0.0 \\
\hline \multirow{3}{*}{ B3LYP-D3 ${ }^{A B C} / 6-311 G^{*} / / H F-3 c-027$} & $\mathrm{E}_{\text {tot }}$ & 4.3 & 1.2 & -3.1 & 0.0 \\
\hline & $E_{e l}$ & 1.4 & -2.6 & -4.0 & 0.0 \\
\hline & $E_{\text {disp }}$ & 3.0 & 3.8 & 0.9 & 0.0 \\
\hline \multirow{3}{*}{ B3LYP-D3ABC/6-311G*//B3LYP-D3 ${ }^{A B C} / 6-311 G^{*}$} & $E_{\text {tot }}$ & 18.7 & 3.8 & -14.9 & -0.8 \\
\hline & $\mathrm{E}_{\mathrm{el}}$ & 13.2 & -3.3 & -16.6 & -0.8 \\
\hline & $E_{\text {disp }}$ & 5.5 & 7.1 & 1.6 & 0.0 \\
\hline \multirow{3}{*}{ B3LYP-D3ABC/TZP//HF-3c-027 } & $\mathrm{E}_{\text {tot }}$ & 5.3 & 1.9 & -3.4 & -0.3 \\
\hline & $E_{e l}$ & 2.3 & -2.0 & -4.3 & -0.3 \\
\hline & $E_{\text {disp }}$ & 3.0 & 3.8 & 0.9 & 0.0 \\
\hline \multirow{3}{*}{ B3LYP-D3 ${ }^{A B C} / T Z P / / B 3 L Y P-D 3^{A B C} / T Z P$} & $E_{\text {tot }}$ & 6.1 & 1.0 & -5.2 & 0.2 \\
\hline & $\mathrm{E}_{\mathrm{el}}$ & 3.9 & -2.6 & -6.5 & 0.2 \\
\hline & $\mathrm{E}_{\text {disp }}$ & 2.2 & 3.6 & 1.3 & 0.0 \\
\hline \multirow{3}{*}{ B3LYP-D3ABC/QZP//HF-3c-027 } & $\mathrm{E}_{\text {tot }}$ & 5.5 & 1.6 & -3.9 & -0.2 \\
\hline & $\mathrm{E}_{\mathrm{el}}$ & 2.6 & -2.2 & -4.8 & -0.2 \\
\hline & $E_{\text {disp }}$ & 3.0 & 3.8 & 0.9 & 0.0 \\
\hline \multirow{3}{*}{ B3LYP-D3ABC/QZP//B3LYP-D3ABC/QZP } & $E_{\text {tot }}$ & 4.7 & 0.9 & -3.8 & 0.0 \\
\hline & $\mathrm{E}_{\mathrm{el}}$ & 3.3 & -1.5 & -4.8 & 0.0 \\
\hline & $E_{\text {disp }}$ & 1.4 & 2.4 & 1.0 & 0.0 \\
\hline \multirow{3}{*}{ PBE-D3ABC/TZP//HF-3c-027 } & $\mathrm{E}_{\text {tot }}$ & 4.6 & 1.1 & -3.5 & -0.3 \\
\hline & $\mathrm{E}_{\mathrm{el}}$ & 2.6 & -1.4 & -4.0 & -0.3 \\
\hline & $E_{\text {disp }}$ & 2.0 & 2.5 & 0.5 & 0.0 \\
\hline \multirow{3}{*}{$\mathrm{PBE}-\mathrm{D} 33^{\mathrm{ABC}} / \mathrm{TZP} / / \mathrm{PBE}-\mathrm{D} 3^{\mathrm{ABC}} / \mathrm{TZP}$} & $E_{\text {tot }}$ & 16.0 & 0.9 & -15.0 & -0.2 \\
\hline & $\mathrm{E}_{\mathrm{el}}$ & 12.3 & -4.1 & -16.4 & -0.2 \\
\hline & $E_{\text {disp }}$ & 3.6 & 5.0 & 1.4 & 0.0 \\
\hline \multirow{3}{*}{ HSE06-D3ABC/TZP//HF-3c-027 } & $\mathrm{E}_{\text {tot }}$ & 4.8 & 1.2 & -3.6 & -0.3 \\
\hline & $\mathrm{E}_{\mathrm{el}}$ & 3.0 & -0.9 & -3.9 & -0.3 \\
\hline & $E_{\text {disp }}$ & 1.8 & 2.1 & 0.3 & 0.0 \\
\hline \multirow{3}{*}{ HSE06-D3ABC/TZP//HSE06-D3ABC/TZP } & $E_{\text {tot }}$ & 14.2 & 0.4 & -13.8 & -0.2 \\
\hline & $\mathrm{E}_{\mathrm{el}}$ & 10.9 & -3.7 & -14.6 & -0.2 \\
\hline & $E_{\text {disp }}$ & 3.3 & 4.1 & 0.8 & 0.0 \\
\hline
\end{tabular}


Table S12. Effect of integral tolerance parameters on the collagen model geometry. Analysis carried out on helices with GGO and GAO compositions, and 7/2 and 10/3 helicities. Calculations are performed at B3LYP-D3ABC/TZP level. Two different set of tolerances on integrals are compared tol 1 and tol2 (tol1= 6666 14; tol2= 777725 ).

\begin{tabular}{|c|c|c|c|c|c|c|c|c|c|c|c|c|c|c|c|}
\hline & & Gly & & & $x$ & & & & & & & & & & \\
\hline & $\varphi$ & $\psi$ & $\omega$ & $\varphi$ & $\psi$ & $\omega$ & $\varphi$ & $\psi$ & $\omega$ & $x^{2}$ & EC1 & EC4 & EC5 & EC2 & cell \\
\hline GGO-7/2 tol1 & -72.0 & -171.0 & 176.7 & -87.2 & -171.9 & 163.2 & -56.5 & 160.8 & 150.5 & 43.7 & 2.42 & 2.23 & 3.03 & 1.99 & 20.30 \\
\hline GGO-7/2 tol2 & -71.8 & -171.8 & 176.2 & -86.6 & -172.5 & 163.6 & -56.2 & 160.9 & 150.7 & 43.7 & 2.42 & 2.23 & 3.03 & 1.99 & 20.28 \\
\hline GAO-7/2 tol1 & -65.2 & 174.9 & 170.5 & -72.2 & 170.1 & 168.3 & -57.1 & 160.7 & 161.2 & 39.9 & 2.21 & 3.23 & 3.12 & 2.06 & 19.94 \\
\hline GAO-7/2 tol2 & -65.2 & 174.8 & 170.5 & -72.1 & 170.0 & 168.3 & -57.0 & 160.6 & 161.2 & 40.0 & 2.21 & 3.23 & 3.12 & 2.06 & 19.94 \\
\hline GGO-10/3 tol1 & -66.6 & 168.6 & 172.0 & -78.9 & 162.7 & 171.1 & -59.6 & 159.8 & 164.6 & 39.5 & 2.04 & 4.25 & 2.55 & 2.09 & 29.66 \\
\hline GGO-10/3 tol2 & -67.0 & 168.2 & 172.6 & -77.7 & 160.7 & 170.8 & -59.1 & 158.8 & 166.1 & 39.4 & 2.02 & 4.36 & 2.54 & 2.09 & 29.64 \\
\hline GAO- $10 / 3$ tol 1 & -66.4 & 166.7 & 172.3 & -72.1 & 156.6 & 168.2 & -58.1 & 157.4 & 168.8 & 38.7 & 1.99 & 4.63 & 2.62 & 2.11 & 29.29 \\
\hline GAO-10/3 tol2 & -66.6 & 166.9 & 172.6 & -71.7 & 156.2 & 167.7 & -57.7 & 156.9 & 169.0 & 38.6 & 1.98 & 4.66 & 2.64 & 2.11 & 29.26 \\
\hline
\end{tabular}

Table S13. Effect of integral tolerance parameters on the collagen model $B E^{\star}$. Analysis carried out on helices with GGO and GAO compositions, and 7/2 and 10/3 helicities. Calculations are performed at B3LYP-D3ABC/TZP level. Two different set of tolerances on integrals are compared tol1 and tol2 (tol1= 6666 14; tol2= 7777 25). Data are reported in $\mathrm{kJ} \mathrm{mol}^{-1} \cdot$ triplet $^{-1}$.

\begin{tabular}{cccc|cc}
\hline \hline & & GGO Tol1 & GGO Tol2 & GAO Tol1 & GAO Tol2 \\
\hline \multirow{3}{*}{$7 / 2$} & $\mathrm{E}_{\text {tot }}$ & 97.2 & 96.7 & 89.9 & 89.9 \\
& $\mathrm{E}_{\mathrm{el}}$ & 45.9 & 45.6 & 38.4 & 38.4 \\
& $\mathrm{E}_{\text {disp }}$ & 51.3 & 51.0 & 51.5 & 51.4 \\
\multirow{3}{*}{$10 / 3$} & $\mathrm{E}_{\text {tot }}$ & 83.7 & 83.8 & 83.5 & 83.6 \\
& $\mathrm{E}_{\mathrm{el}}$ & 36.2 & 36.8 & 34.3 & 34.6 \\
& $\mathrm{E}_{\text {disp }}$ & 47.5 & 47.0 & 49.2 & 49.0 \\
\hline \hline
\end{tabular}




\section{References}

(1) Bella, J.; Berman, H. M. Crystallographic Evidence for $\mathrm{C}(\alpha)-\mathrm{H} \ldots \mathrm{O}=\mathrm{C}$ Hydrogen Bonds in a Collagen Triple Helix. J. Mol. Biol. 1996, 264 (4), 734-742.

(2) Cutini, M.; Bocus, M.; Ugliengo, P. Decoding Collagen Triple Helix Stability by Means of Hybrid DFT Simulations. J. Phys. Chem. B 2019, 123, 7354-7364.

(3) Bella, J. Collagen Structure: New Tricks from a Very Old Dog. Biochem. J. 2016, 473 (8), 1001-1025. 